\title{
Targeted Deletion of ERK5 MAP Kinase in the Developing Nervous System Impairs Development of GABAergic Interneurons in the Main Olfactory Bulb and Behavioral Discrimination between Structurally Similar Odorants
}

\author{
Junhui Zou, ${ }^{1}$ Yung-Wei Pan, ${ }^{2}$ Zhenshan Wang, ${ }^{3}$ Shih-Yu Chang, ${ }^{1}$ Wenbin Wang, ${ }^{1}$ Xin Wang, ${ }^{4}$ \\ Cathy Tournier, ${ }^{4}$ Daniel R. Storm, ${ }^{3}$ and Zhengui Xia ${ }^{1,2,3}$ \\ ${ }^{1}$ Toxicology Program in the Department of Environmental and Occupational Health Sciences, ${ }^{2}$ Graduate Program in Molecular and Cellular Biology, and \\ ${ }^{3}$ Department of Pharmacology, University of Washington, Seattle, Washington 98195-7234, and ${ }^{4}$ Faculty of Life Sciences, University of Manchester, \\ Manchester M13 9PT, United Kingdom
}

ERK5 MAP kinase is highly expressed in the developing nervous system and has been implicated in promoting the survival of immature neurons in culture. However, its role in the development and function of the mammalian nervous system has not been established in vivo. Here, we report that conditional deletion of the erk5 gene in mouse neural stem cells during development reduces the number of GABAergic interneurons in the main olfactory bulb (OB). Our data suggest that this is due to a decrease in proliferation and an increase in apoptosis in the subventricular zone and rostral migratory stream of ERK5 mutant mice. Interestingly, ERK5 mutant mice have smaller $\mathrm{OB}$ and are impaired in odor discrimination between structurally similar odorants. We conclude that ERK5 is a novel signaling pathway regulating developmental $\mathrm{OB}$ neurogenesis and olfactory behavior.

\section{Introduction}

Humans and other vertebrates detect and distinguish between thousands of different odorants, a function that is important for human nutrition and also critical for the survival of many animal species. Olfactory signals detected by sensory neurons in the main olfactory epithelium are transmitted to the main olfactory bulb (OB) for processing and integration. In the OB, axons from olfactory sensory neurons contact the primary dendrites of glutamatergic mitral and tufted cells, the main excitatory neurons in the OB. Mitral cells, the major source of output from the OB, project axons into the olfactory cortex of the brain (White, 1965; Haberly and Price, 1977; Schwob and Price, 1978). Odor information received by mitral cells is processed by a complex local inhibitory microcircuit primarily formed by granule cells in the granule cell layer and by periglomerular neurons (Lledo et al.,

Received Dec. 16, 2011; revised Jan. 30, 2012; accepted Feb. 2, 2012.

Author contributions: J.Z., D.R.S., and Z.X. designed research; J.Z., Y.-W.P., Z.W., S.-Y.C., and W.W. performed research; Y.-W.P., X.W., and C.T. contributed unpublished reagents/analytic tools; J.Z., D.R.S., and Z.X. analyzed data; J.Z., D.RS., and Z.X. wrote the paper.

This work was supported by the National Institutes of Health (AG19193 to Z.X., DC004156 to D.R.S., and T32HD007183 and F31DC011216 to Y.W.P.), and facilitated by Grant P30 HD02274 from the National Institute of Child Health and Human Development. We thank Dr. Bradford C. Berk from the University of Rochester for transfer of ERK5 ${ }^{\text {loxP/loxP }}$ mice, members of the Hevner laboratory for Nissl staining protocols, members of the Storm and Xia laboratories for technical assistance on behavior tests and critical reading of the manuscript, Drs. Robert Hevner and Lisa Horowitz for scientific discussion, and Glen MacDonald for technical assistance on imaging.

Correspondence should be addressed to Zhengui Xia, Department of Environmental and Occupational Health Sciences, University of Washington, Health Science Building, Box 357234, Room F561C, Seattle, WA 98195-7234. E-mail:zxia@u.washington.edu.

DOI:10.1523/JNEUROSCI.6260-11.2012

Copyright $\odot 2012$ the authors $\quad 0270-6474 / 12 / 324118-15 \$ 15.00 / 0$
2004; Adam and Mizrahi, 2010). The production of these inhibitory interneurons begins embryonically and continues postnatally throughout the life of the animal, with peak production occurring between embryonic day (E) 18.5 to postnatal day (P) 14 (Hinds, 1968; Rosselli-Austin and Altman, 1979; Batista-Brito et al., 2008). During embryonic development, OB interneurons are generated from the lateral ganglionic eminence and dorsal telencephalon, while postnatally generated $\mathrm{OB}$ interneurons are derived from the anterior subventricular zone (SVZ) of the lateral ventricles, migrating along the rostral migratory stream (RMS) to the OB (Luskin, 1998; Wichterle et al., 2001; Yun et al., 2001; Alvarez-Buylla and Garcia-Verdugo, 2002; Stenman et al., 2003). Several transcription factors are known to regulate the genesis of these interneurons during development including the distal-less (family of proteins, Pax6 and Sp8 (Dellovade et al., 1998; Long et al., 2003; Kohwi et al., 2005; Waclaw et al., 2006; Long et al., 2007; Brill et al., 2008). However, very little is known about signaling pathways that control $\mathrm{OB}$ neurogenesis during development.

ERK5 is a member of the MAP kinase super family that is comprised of ERK1/2, JNK, p38, and ERK5 (Lee et al., 1995; Zhou et al., 1995). The N-terminal kinase domain of ERK5 is highly homologous to the prototypical ERK1/2 and to a lesser degree, p38 and JNK. However, ERK5 contains a large C terminus not found in other MAP kinases, suggesting unique regulatory properties and functions of ERK5. Indeed, ERK5-null mice are embryonically lethal (Regan et al., 2002; Sohn et al., 2002; Yan et al., 2003), suggesting that ERK5 has distinct biological functions that cannot be compensated for by ERK1/2 or other MAP kinases. Although ERK1/2 and ERK5 are the principle MAP kinases acti- 
vated by neurotrophins in neurons, ERK5 is phosphorylated and activated by MEK5, an upstream MAP kinase kinase specific for ERK5 (English et al., 1995; Zhou et al., 1995; Cavanaugh et al., 2001; Wang et al., 2006a). Furthermore, unlike ERK1/2, ERK5 is not activated by cAMP or calcium signals in neurons (Cavanaugh et al., 2001).

In cell culture, neurotrophin activation of ERK5 promotes the survival of newborn but not mature neurons (Watson et al., 2001; Liu et al., 2003; Shalizi et al., 2003; Finegan et al., 2009). Furthermore, ERK5 specifies cultured cortical stem/progenitor cells toward a neuronal lineage during development by phosphorylating and modulating the activity of neurogenin 1, a proneural transcription factor (Liu et al., 2006; Cundiff et al., 2009). In this study, we investigated the importance of ERK5 for the development of the $\mathrm{OB}$ and the ability of mice to distinguish between different odorants. Because germ-line deletion of ERK5 is embryonically lethal at around E9.5 (Regan et al., 2002; Sohn et al., 2002; Yan et al., 2003), a time point before the neural tube develops, we generated a conditional knock-out mouse strain that allowed us to delete the erk5 gene in neural stem cells during development. Here, we report that ERK5 mutant mice have smaller $\mathrm{OB}$, fewer GABAergic interneurons in the $\mathrm{OB}$, and are unable to discriminate between structurally similar odorants.

\section{Materials and Methods}

\section{Animals and tissue preparation}

The ERK5 ${ }^{\text {loxP/loxP }}$ mouse line was generated by Dr. Cathy Tournier (Wang et al., 2006c) and transferred from Dr. Bradford C. Berk's laboratory. Nestin-Cre mice (Tronche et al., 1999) were purchased from Jackson Laboratories with the strain name B6.Cg(SJL)-TgN(NesCre) and crossed with ERK5 ${ }^{\text {loxP/loxP }}$ mice to generate Nestin-Cre/ERK5 ${ }^{\text {loxP/ }}$ loxP mice in which erk5 is conditionally deleted in Nestin-expressing neural stem cells (ERK5 cKO). Male Nestin-Cre/ERK5 ${ }^{\text {loxP/+ }}$ and female ERK5 ${ }^{\operatorname{loxP} / \mathrm{loxP}}$ mice were mated to generate experimental Nestin-Cre/ ERK5 ${ }^{\text {loxP/loxP }}$ animals, while ERK5 ${ }^{\text {loxP/loxP }}$ and ERK5 ${ }^{\text {loxP/+ }}$ littermates were used as controls (ERK5 WT). For studies using embryos, the day of vaginal plug was designated as E0.5. For embryos or P0 (day of birth) and P7 pups, brains were dissected and fixed in $4 \%$ paraformaldehyde (PFA) (Fisher Scientific) in $0.1 \mathrm{~m} \mathrm{pH} 7.4$ PBS overnight. Animals beyond $14 \mathrm{~d}$ of age were anesthetized and perfused transcardially with 4\% PFA and then postfixed with $4 \%$ PFA overnight. All brains were cryoprotected in a gradient of sucrose to $30 \%(\mathrm{w} / \mathrm{v})$, frozen in TFM embedding medium (Triangle Biomedical Sciences), and cut sagittally or coronally at $14 \mu \mathrm{m}$ in thickness using a cryostat (Leica, CM1850) and mounted onto Superfrost Plus slides (VWR). Four to six brains were stained and examined for histological or immunohistological analysis for each data point. All experiments were performed in accordance with the University of Washington Institutional Animal Care and Use Committee.

\section{BrdU labeling}

Bromodeoxyuridine (5' -bromo-2' -deoxyuridine; BrdU) (100 mg/kg; Sigma) was dissolved in $0.9 \%$ sodium chloride $/ 0.007 \% \mathrm{NaOH}$ and administered intraperitoneally to P0, P7, and P14 pups (Shingo et al., 2003; Li et al., 2009; van Velthoven et al., 2010). Animals were killed $2 \mathrm{~h}$ postinjection.

\section{Immunohistochemistry}

Immunohistochemistry (IHC) was performed per standard protocol. Briefly, after washing with PBS to remove mounting medium, PFAfixed cryosections were treated with $1 \%$ SDS for $10 \mathrm{~min}$ to permeabilize the sample and blocked with blocking buffer (PBS $+0.1 \%$ Triton $(\mathrm{PBST})+5 \% \mathrm{BSA}+5 \%$ normal goat serum or normal donkey serum) for $>2 \mathrm{~h}$ at room temperature. Where IHC for BrdU visualization was required, brain sections were washed as before with PBS, and subjected to $\mathrm{HCl}$ antigen retrieval method by first rinsing in water for $5 \mathrm{~min}$, in ice-cold $1 \mathrm{~N} \mathrm{HCl}$ for $10 \mathrm{~min}$, in $2 \mathrm{~N} \mathrm{HCl}$ for $30 \mathrm{~min}$ at
Table 1. List of odorants used in electro-olfactogram measurement and olfaction tests

\begin{tabular}{|c|c|c|}
\hline Experiments & Odorants & Concentrations \\
\hline \multirow[t]{4}{*}{ Electro-olfactogram } & Ciltralva & $1 \mathrm{~mm}$ \\
\hline & Ethyl vanillin & $100 \mu \mathrm{M}$ \\
\hline & S-(-)-Limonene (Limonene $(-))$ & $10 \mathrm{~mm}$ \\
\hline & Isoamyl acetate & $1 \mathrm{~mm}$ \\
\hline \multirow[t]{3}{*}{ Olfactory habituation } & 1-0ctanol & $100 \mu \mathrm{M}$ \\
\hline & Benzaldehyde & $100 \mu \mathrm{M}$ \\
\hline & Ethyl vanillin & $100 \mu \mathrm{M}$ \\
\hline \multirow{5}{*}{$\begin{array}{l}\text { Cotton-tip-based olfactory fine } \\
\text { discrimination }\end{array}$} & $\mathrm{R}-(+)$-Limonene (Limonene $(+))$ & $10 \mathrm{~mm}$ \\
\hline & Limonene (-) & $10 \mathrm{~mm}$ \\
\hline & 1-Butanol & $10 \mathrm{~mm}$ \\
\hline & 1-Pentanol & $10 \mathrm{~mm}$ \\
\hline & Limonene (+) & $10 \mathrm{~mm}$ \\
\hline Cotton-tip-based odor preference & Limonene (-) & $10 \mathrm{~mm}$ \\
\hline \multirow{6}{*}{$\begin{array}{l}\text { Sand-digging-based olfactory } \\
\text { discrimination }\end{array}$} & Isoamyl acetate & $10 \mathrm{~mm}$ \\
\hline & Ciltralva & $10 \mathrm{~mm}$ \\
\hline & Limonene $(+)$ & $100 \mathrm{~mm}$ \\
\hline & Limonene (-) & $100 \mathrm{~mm}$ \\
\hline & 1-Butanol & $100 \mathrm{~mm}$ \\
\hline & 1-Pentanol & $100 \mathrm{~mm}$ \\
\hline
\end{tabular}

$37^{\circ} \mathrm{C}$, and finally neutralized by rinsing $3 \times 5 \mathrm{~min}$ in $0.5 \mathrm{M} \mathrm{pH} 8.0$ borate buffer. Brain sections were then incubated with primary antibodies in blocking buffer for $24 \mathrm{~h}$ at $4^{\circ} \mathrm{C}$ and secondary antibodies conjugated with Alexa Fluor 488 or Alexa Flour 594 (1:500; Invitrogen) for $2 \mathrm{~h}$ at room temperature. Nuclei were visualized with 2.5 $\mu \mathrm{g} / \mathrm{ml}$ Hoechst 33342 (Invitrogen). Sections were washed with PBST after each step. Finally, brain sections were mounted with anti-fade Aqua Poly/Mount (Polysciences). Primary antibodies used were as follows: affinity-purified rabbit anti-ERK5 (1:200)(Cavanaugh et al., 2001), rabbit anti- type-3 adenylyl cyclase (AC3; 1:200; Santa Cruz Biotechnology), mouse anti-tyrosine hydroxylase (TH; 1:1000; Sigma), mouse anti-GAD67 (1:2000; Millipore Bioscience Research Reagents), mouse anti-NeuN (1:500; Millipore), mouse anti-Calretinin (1:500; Santa Cruz Biotechnology), mouse anti-Calbindin (1:500; Santa Cruz Biotechnology), mouse anti-Reelin (1:1000; Abcam), goat anti-olfactory marker protein (OMP; 1:2000; WAKO), mouse antiSox2 (1:200; R\&D Systems), mouse anti-polysialic acid-neural cell adhesion molecule (PSA-NCAM; 1:200; Developmental Studies Hybridoma Bank), rabbit anti-active caspase3 (1:500; Cell Signaling Technology), and rat anti-BrdU (1:500; AbD Serotec).

\section{TUNEL}

Every third parasagittal section or fifth coronal section of each brain was subjected to TUNEL assay by using the DeadEnd fluorometric TUNEL system from Promega per manufacturer's instruction. Total number of $\mathrm{TUNEL}^{+}$cells in the area of anterior SVZ and RMS from parasagittal sections or OB from coronal sections were quantified.

\section{Image capturing and processing}

All images were captured with a Zeiss upright fluorescence microscope with numerical aperture (NA) $0.075 / 2.5 \times$, NA $0.16 / 5 \times$, NA $0.3 / 10 \times$, NA $0.5 / 20 \times$, and NA $0.75 / 40 \times$ air lenses, or NA $1.40 / 63 \times$ oil-immersion lens. Images were uniformly adjusted for color, brightness, and contrast with Adobe Photoshop CS3. ImageJ software was used to quantify immunostaining intensity. Three aligned sections were quantified for anti-GAD67 immunostaining intensity per OB. For each section, four pictures at $20 \times$ magnification sampled at the dorsal, medial, lateral, and ventral OB were captured. The regions of granule cell layer and glomerular layer were outlined under Hoechst staining. For quantification of anti-PSA-NCAM immunostaining intensity along the anterior SVZ (SVZa)-RMS-OB path, three aligned parasagittal sections were analyzed per brain. For each section, three pictures at $20 \times$ magnification sampled at the SVZa, RMS, and the core of $\mathrm{OB}$ were captured. For quantification of anti-Sox2 immuno- 


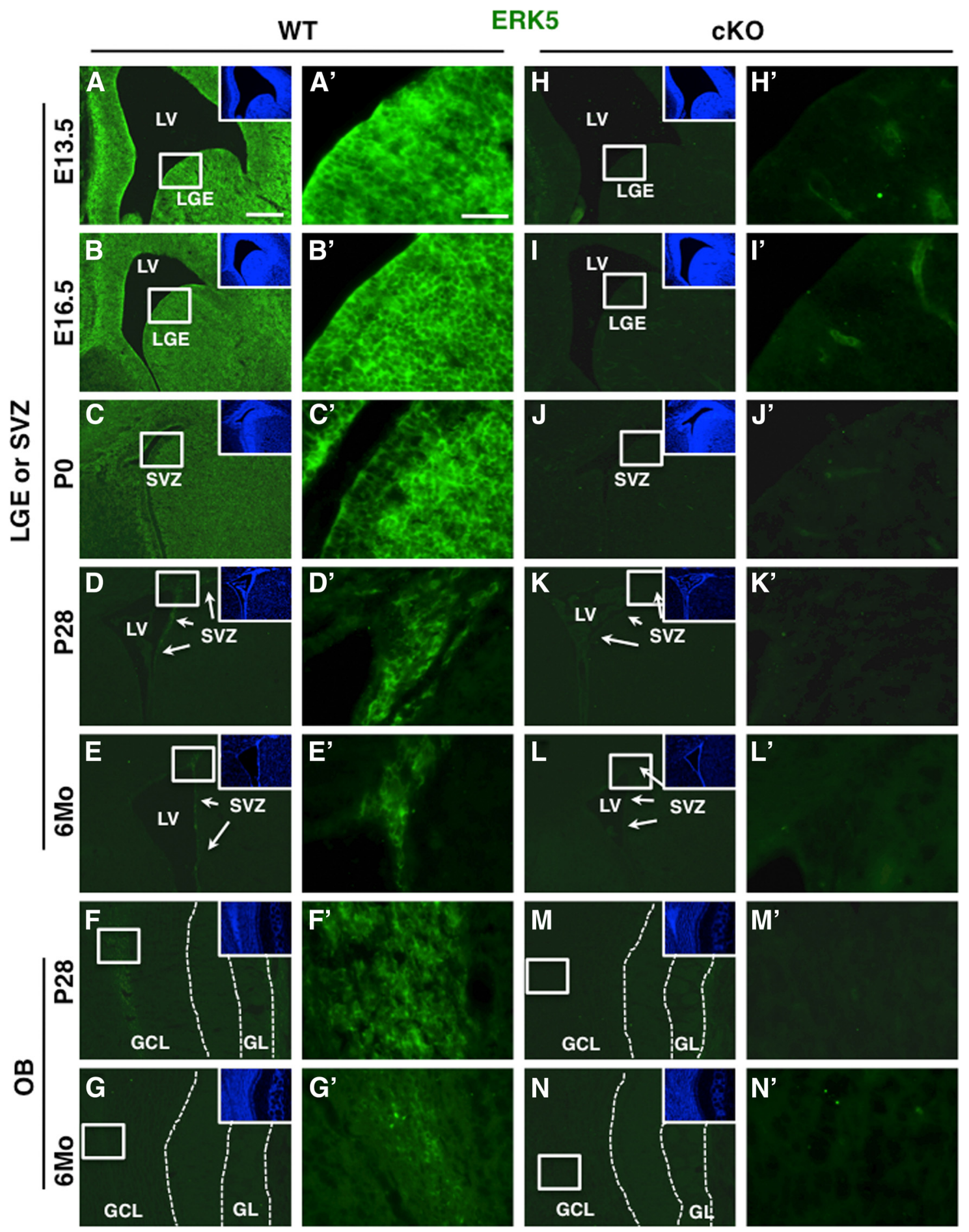

Figure 1. ERK5 protein expression in WT and cK0 littermates. Coronal sections were prepared from E13.5, E16.5, P0, P28, and 6 month-old (6Mo) brains and immunostained with an affinity-purified anti-ERK5 antibody. $\boldsymbol{A}-\mathbf{G}$, ERK5 protein expression in WT mouse brains. $\boldsymbol{H}-\boldsymbol{N}$, ERK5 protein expression in cK0 mouse brains. Insets, $\boldsymbol{A}-\boldsymbol{N}$, Hoechst-stained images to orient the location of the images. $\boldsymbol{A}^{\prime}-\boldsymbol{N}^{\prime}$, High-magnification images of the corresponding boxed area $(\boldsymbol{A}-\boldsymbol{N}) . \boldsymbol{D}, \boldsymbol{E}, \boldsymbol{K}, \boldsymbol{L}$, Arrows point to the SVZ. LGE, Lateral ganglionic eminence; LV, lateral ventricle; GL, glomerular layer; GCL, granule cell layer. Scale bars: (in $\boldsymbol{A}) \boldsymbol{B}-\boldsymbol{N}^{\prime}, 200 \mu \mathrm{m}$; (in $\boldsymbol{A}^{\prime}$ ) $\boldsymbol{B}^{\prime}-\boldsymbol{N}^{\prime}, 40 \mu \mathrm{m}$.

staining in the SVZ, every eighth coronal section was immunostained and the entire SVZ in each section was captured in multiple images under a $20 \times$ lens. The region of SVZ in each image was outlined under Hoechst staining, and the total Sox 2 staining intensity of the outlined region was measured for each image. The accumulative Sox2 intensity per SVZ was calculated as the sum of the total intensity from each image multiplied by 8

\section{Stereology}

Quantification of immunostained cells

The density of $\mathrm{NeuN}^{+}$cells in both granule cell layer and glomerular layer of $\mathrm{OB}$, the density of Calretinin ${ }^{+}$cells in granule cell layer of the $\mathrm{OB}$, and the total number of $\mathrm{BrdU}^{+}$cells in the anterior SVZ and RMS were quantified using the Optical Fractionator probe of Stereo Investigator software (MBF Bioscience). Briefly, every fifth serial coronal sec- 
A
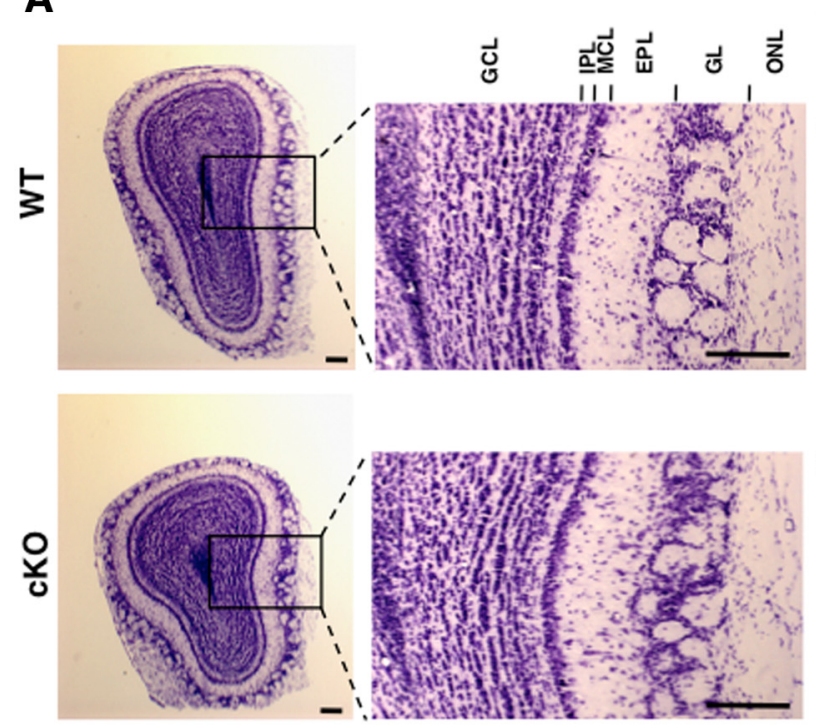

B

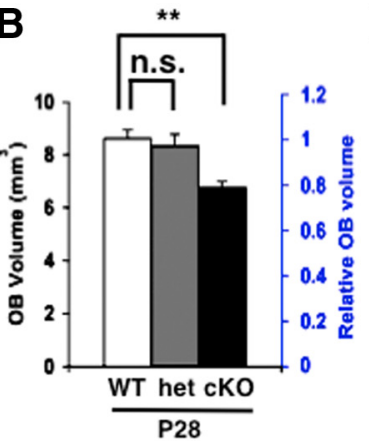

D

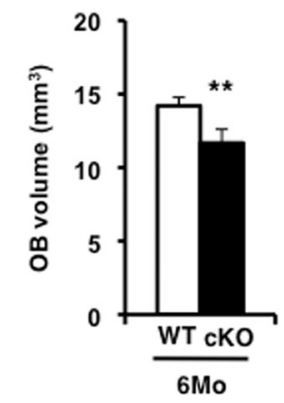

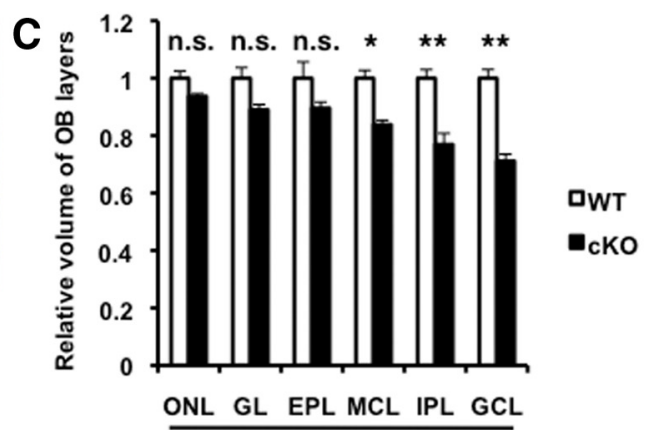

P28

Figure 2. ERK5 CK0 mice have smaller OB. A, ERK5 deletion does not affect the overall lamina structure of the OB at P28. Images are Nissl-stained coronal sections. Scale bar, $200 \mu \mathrm{m}$. B, ERK5 deletion results in a smaller $O B$ at P28. Data are unbiased stereological measurements of the OB volume from ERK5 CKO, ERK5 WT, or heterozygous (het) littermates. $C$, Stereological measurement of the volumes for each layer of the $0 B$ at P28. D, ERK5 CKO mice still have smaller OB at 6 months of age. ONL, Olfactory nerve layer; GL, glomerular layer; EPL, external plexiform layer; MCL, mitral cell layer; IPL, internal plexiform layer; GCL, granule cell layer. $n=5$ per genotype. n.s., not significant; ${ }^{*} p<0.05 ;{ }^{* *} p<0.01$.
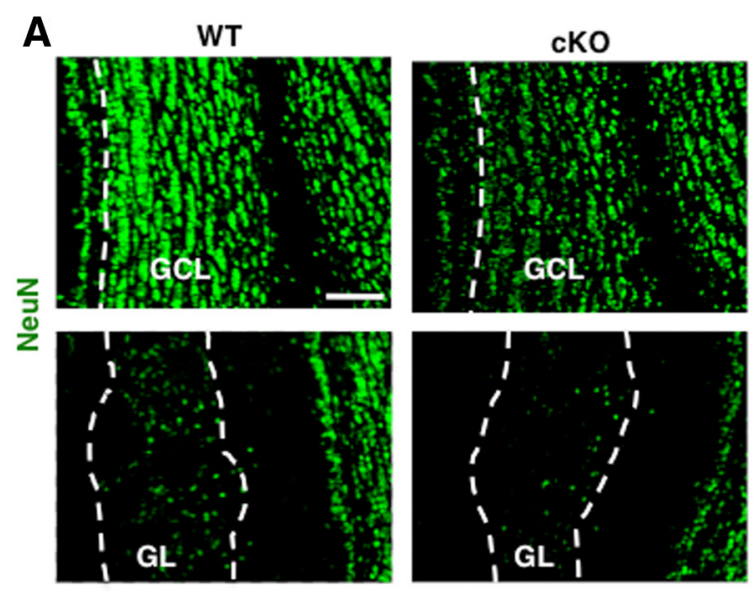

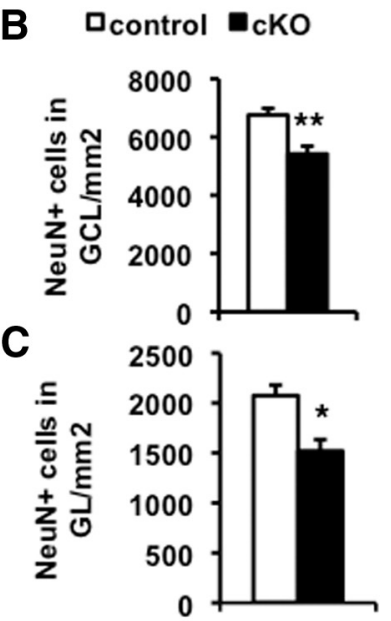

Figure 3. ERK5 $\mathrm{CKO}$ mice have fewer neurons in the $0 B$. $A$, Representative images of NeuN immunostaining in the granule cell layer (GCL) and glomerular layer (GL) of the OB from P28 ERK5 WT and CKO mice. B, C, Stereological quantification of NeuN ${ }^{+}$cell density in $\mathrm{GCL}(\boldsymbol{B})$ and $\mathrm{GL}$ (C). Scale bar: (in $\boldsymbol{A}) \boldsymbol{A}-\boldsymbol{C}, 100 \mu \mathrm{m} .{ }^{*} p=0.05 ; p=0.01$.

Size measurement of brain regions Volumetric measurement of the $\mathrm{OB}$ and its individual layers or substructures as well as anterior SVZ-RMS and lateral ventricles was conducted using the Cavalieri Estimator probe of Stereo Investigator software. Every fifth serial coronal section stained with cresyl violet was used for OB measurement. Every third serial parasagittal section was used for the measurement of anterior SVZ-RMS at P0, and every fourth or eighth coronal section stained with Hoechst was used for the measurement of lateral ventricles at $\mathrm{P} 0$ or $\mathrm{P} 28$, respectively.

\section{Electro-olfactogram measurement}

Electro-olfactogram (EOG) studies in the main olfactory epithelium were performed as described previously (Wong et al., 2000; Trinh and Storm, 2003). Briefly, awake mice were killed by cervical dislocation and skulls were cut in half along the midline. The septal cartilage was removed to expose the olfactory turbinates. Olfactory turbinates from both sides were used for recordings. The EOG was recorded with an agar- and saline- filled glass microelectrode in contact with the apical surface

tion was used for cell counting in the OB, and every third parasagittal section for cell counting in the SVZ and RMS. For each section, the region of interest was outlined under the $5 \times$ objective of a Zeiss upright fluorescence microscope, and cell counting was performed under the $40 \times$ or $60 \times$ objective with the counting frame set at $50 \times 50 \mu \mathrm{m}^{2}$. At least 300 cells were sampled for each brain region per animal. Calretinin ${ }^{+}, \mathrm{TH}^{+}$, and Calbindin ${ }^{+}$cells in the glomerular layer of the OB were counted under the $40 \times$ objective and the area of the glomerular layer was measured separately using the Cavalieri Estimator probe of Stereo Investigator software. The density of marker positive cells in each layer was calculated by dividing the total number of cells by the total area of the glomerular layer. of the main olfactory epithelium in the open circuit configuration. Using an automated four-way slider valve, odorants were puffed onto the exposed epithelia for $0.2 \mathrm{~s}$ at a flow rate of $3.1 \mathrm{~L} / \mathrm{min}$. Traces were captured and digitized using a Digidata 1200A (Molecular Devices). The traces were low-pass filtered at $30 \mathrm{~Hz}$ and sampled at $100 \mathrm{~Hz}$. Odorants used in EOG measurements are listed in Table 1.

\section{Behavior assays}

Male mice were used for behavior assays, which generally start when mice are 3 months old and end before they are 6 months old. Mice were 
individually housed and handled twice a day for $7 \mathrm{~d}$ before behavior assays. For all cotton tip-based tests, cotton swabs dipped in mineral oil or odorant solution were hung from the wire top of the animal's home cage with the cotton tips $8 \mathrm{~cm}$ above the cage floor. The duration of animals' sniffing to the cotton swabs was recorded. The sniffing was defined as animals' noses approaching to and within $1 \mathrm{~cm}$ distance to the swabs. Odorants used in olfaction tests are listed in Table 1.

Olfactory habituation/dishabituation test This was performed as described with modifications (Sundberg et al., 1982; Trinh and Storm, 2003). Briefly, naive animals were pretrained with plain mineral oil-laced cotton swabs for four presentations (60 s each, $2 \mathrm{~min}$ intervals) to ensure that subsequent exposure to an odorant-laced cotton swab did not elicit a response due to novelty. The odor habituation/ dishabituation test was then performed by presenting three odorants sequentially, with four presentations for each odorant (60 s each presentation, 2 min intervals). A significant decrease in investigation time during subsequent presentations of the same odorant indicates odor recognition and habituation.

\section{Cotton tip-based olfactory fine}

\section{discrimination test}

After the olfactory habituation test, the same cohort of mice was subjected to the olfactory fine discrimination test. Mice were familiarized with four sequential $60 \mathrm{~s}$ presentations of one odor and then introduced to a structurally very similar odorant for $60 \mathrm{~s}$. The interpresentation interval was $2 \mathrm{~min}$ as above. If a mouse sniffed this structurally similar but new odorant more than it did in the fourth presentation of the first odorant, the animal was considered capable of olfactory fine discrimination.

\section{Odor preference test for structurally} similar odorants

A new cohort of male mice was presented with two cotton tips laced with pairs of structurally similar odorant solution for $3 \mathrm{~min}$. Duration of sniffing toward each cotton tip was recorded.

\section{Sand digging-based olfactory}

discrimination test

Following the odor preference test for structurally similar odorants, the same cohort was subjected to the sand digging-based olfactory discrimination assay, modified from (Mihalick et al., 2000; Wesson et al., 2008). Before and during the training, mice were subjected to food restriction to maintain body weights at their $85-90 \%$ of free-feed level.

An apparatus (see Figure 11A), was constructed and used to present food and sand. The lids of two 96-well culture dishes $(130 \times 80$ $\mathrm{mm}$ ) were glued together to form the platform base and handle. The lid of a $35 \mathrm{~mm}$ culture dish was mounted upside down on each side of the base platform separated by a plastic divider (55 mm depth $\times 50 \mathrm{~mm}$ height), which prevents animals from making simultaneous contact with both dishes. Clean cul-
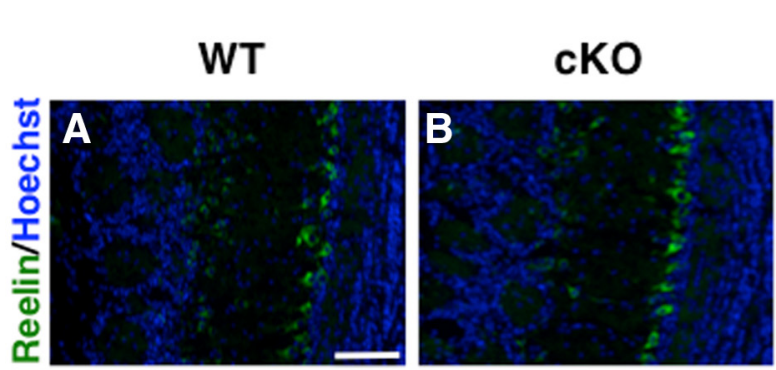

口WT $\boldsymbol{\Xi}_{\mathrm{cKO}}$
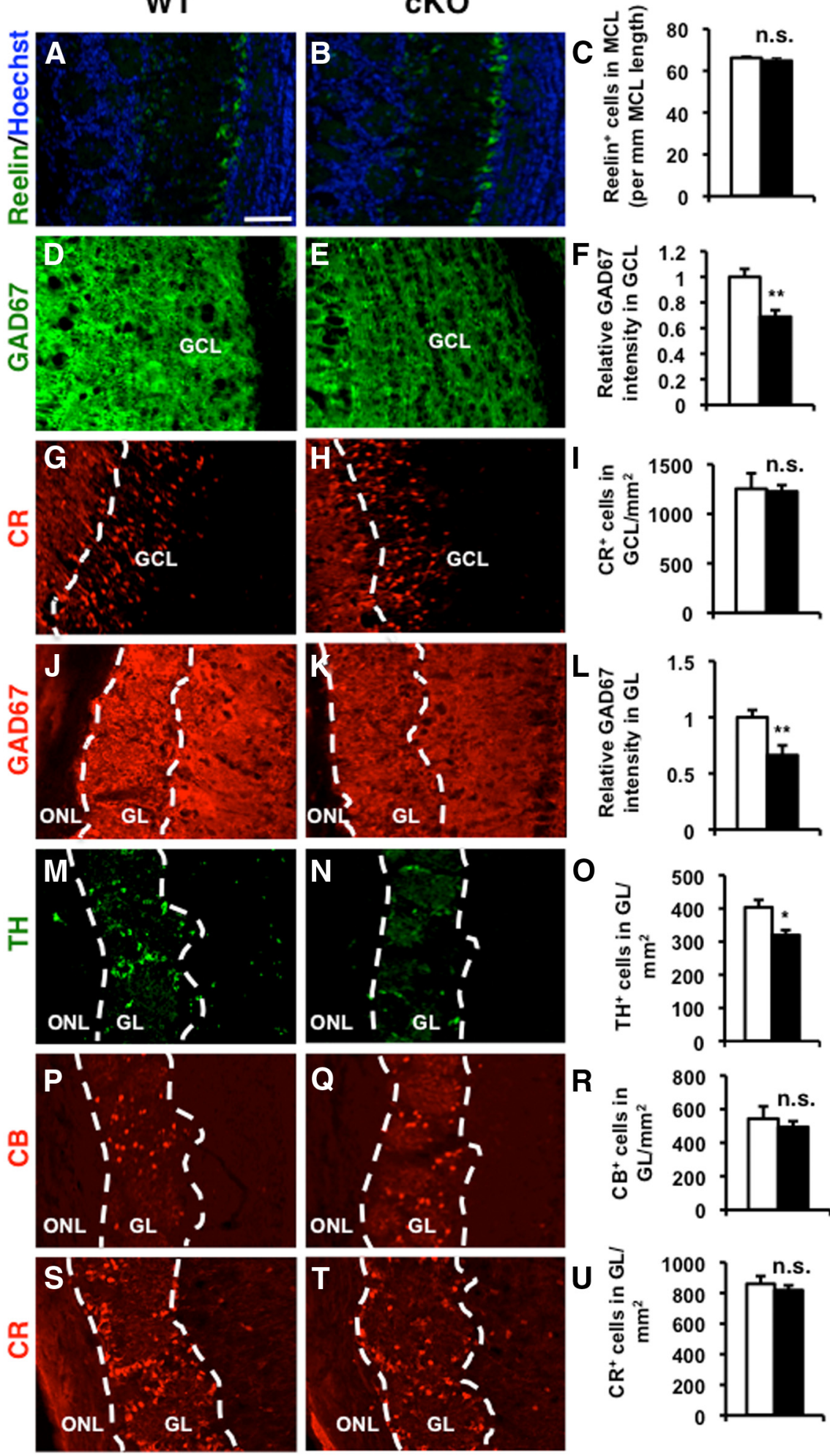

Figure 4. ERK5 deletion reduces the number of GABAergic interneurons in the OB. Coronal sections of the OB from P28 ERK5 WT and CKO mice were analyzed. $\boldsymbol{A}-\boldsymbol{C}$, ERK5 deletion does not change the cell density of mitral cells, identified by anti-Reelin immunostaining. Hoechst staining (blue) was used to identify all nuclei and overall structure. $\boldsymbol{D}-\boldsymbol{F}$, ERK5 deletion significantly reduces immunoreactivity for GAD67, a marker for GABAergic neurons, in the granule cell layer (GCL). G-I, ERK5 deletion does not alter the cell density of Calretinin ${ }^{+}\left(\mathrm{CR}^{+}\right)$cells in $\mathrm{GCL}$. J-L, ERK5 deletion also reduces immunoreactivity for GAD67 in the glomerular layer (GL). $M-\mathbf{O}$, ERK5 $\mathrm{CKO}$ mice have fewer $\mathrm{TH}^{+}$dopaminergic neurons, a subpopulation of interneurons in the $\mathrm{GL}$. $\boldsymbol{P}-\boldsymbol{U}$, ERK5 deletion does not affect the two interneuron subpopulations in the $\mathrm{GL}$ that express calcium binding proteins, Calbindin $(C B ; \boldsymbol{P}-\boldsymbol{R})$ or Calretinin $(C R ; \boldsymbol{S}-\boldsymbol{U})$. Scale bar: (in $\boldsymbol{A}) \boldsymbol{A}-\boldsymbol{U}, 100 \mu \mathrm{m}$. ONL, Olfactory nerve layer. n.s., not significant; ${ }^{*} p<0.05 ;{ }^{* *} p<0.01$. 

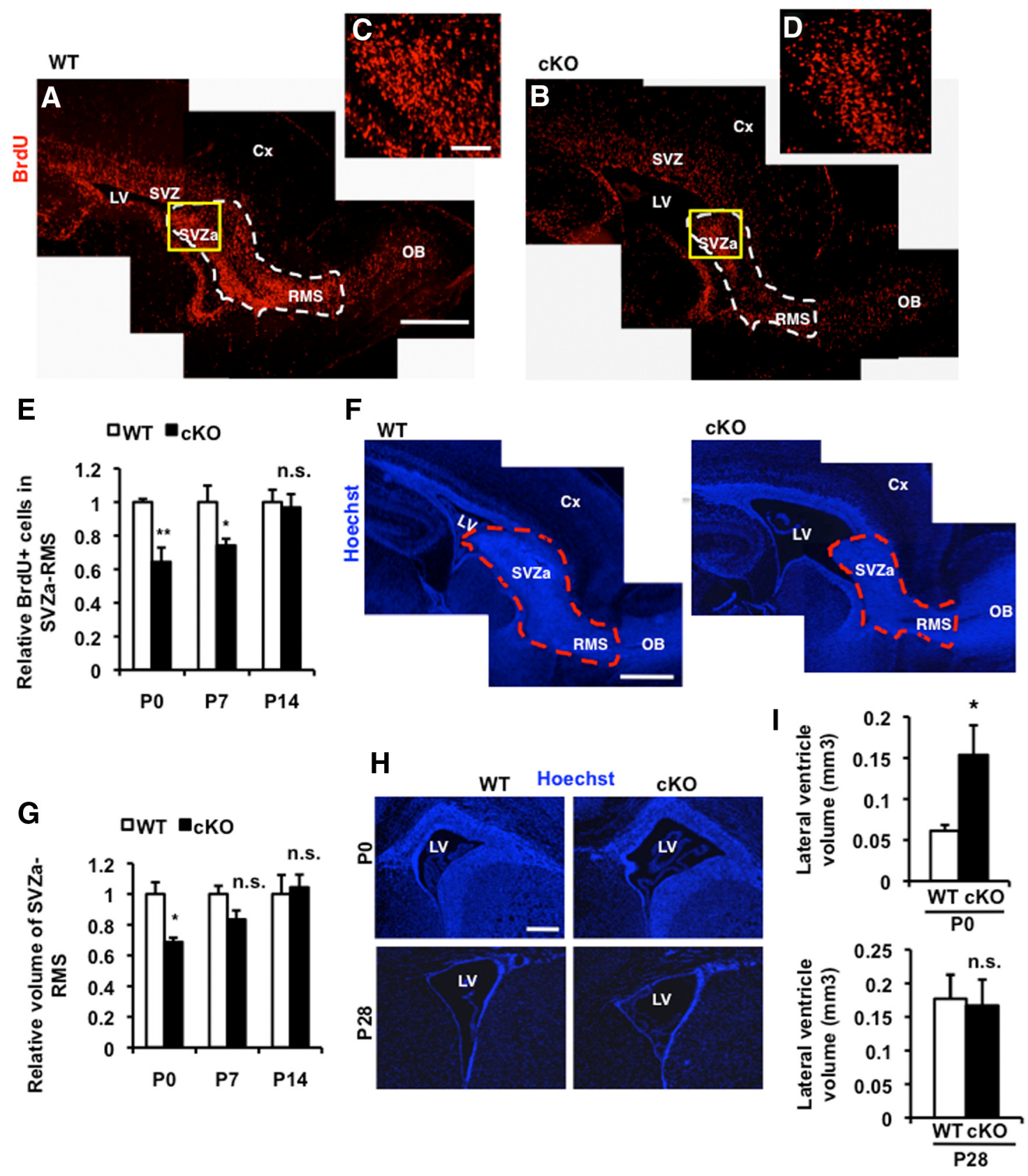

Figure 5. ERK5 deletion attenuates proliferation of progenitor cells in the anterior SVZ and RMS. ERK5 WT and cKO pups at the age of $P 0, P 7$, and P14 were dosed with BrdU and killed $2 \mathrm{~h}$ later. $A, B$, Montaged images of BrdU immunostaining of parasagittal sections of ERK5 WT $(\boldsymbol{A})$ and $C K 0(B)$ brains at PO. Scale bar: (in $A) A, B 500 \mu \mathrm{m}$. $C, D$, High-magnification images of yellow-boxed areas in $\boldsymbol{A}$ and $\boldsymbol{B}$, respectively. Scale bar: (in $\boldsymbol{C} \boldsymbol{C}, \boldsymbol{D}, 100 \mu \mathrm{m}$. $\boldsymbol{E}$, Stereological quantification of total number of BrdU ${ }^{+}$cells in the areas of anterior SVZ(SVZa)-RMS. $\boldsymbol{F}$, Montaged images of Hoechst-stained parasagittal sections of PO brains to visualize the area of anterior SVZa-RMS. The ERK5 CKO brain displays an enlarged lateral ventricle and smaller SVZa-RMS. Scale bar, $500 \mu \mathrm{m}$. G, Stereological quantification of the volume of SVZa-RMS of ERK5 WT and CKO mice. ERK5 deletion reduces the size of SVZa-RMS, the neurogenic region where OB interneurons originate. $\boldsymbol{H}$, Representative images of Hoechst-stained coronal sections of P0 and P28 brains to visualize the size of the lateral ventricles. Scale bar, $200 \mu \mathrm{m}$. I, Stereological quantification of the volume of lateral ventricles of ERK5 WT and CKO mice at P0 and P28. The ERK5 CKO brain displays an enlarged lateral ventricle at PO but not at P28. LV, Left ventricle. n.S., not significant; ${ }^{*} p<0.05 ;{ }^{* *} p<0.01$.

ture dishes $(35 \mathrm{~mm})$, either empty or filled with sand to the top and baited with food reward, were placed on top of the mounted lids on either side. A new dish was used for each mouse and each odorant. The apparatus was cleaned between animals by washing with water, wiping with $95 \%$ ethanol to remove any trace odorant, and sprayed with $70 \%$ ethanol.

Training was performed in each mouse's home cage. The plastic top, wire top, and water bottle were removed and a piece of $20 \times 32 \mathrm{~cm}$ Plexiglas was used to cover the cage. To begin each trial, the Plexiglas cover was first removed, and a cardboard barrier (replaced with a new one between animals and different odorants) was placed inside of the cage to confine the mouse to one end of the cage. This cardboard barrier blocks the view of the mouse while the apparatus with food and sand was lowered into the other end of the cage. The barrier was then quickly removed and the Plexiglas cover repositioned.

Pretraining. The pretraining session consisted of 3 consecutive days during which only one of the two dishes was filled with sand and baited with food reward. On day 1 , the food reward was placed on top of the sand and animals were trained for four trials per block ( 1 min intertrial interval) for two blocks with $4 \mathrm{~h}$ interblock interval, totaling eight trials. The latency of food retrieval in each trial was recorded. If the food was not retrieved within $10 \mathrm{~min}$, the apparatus was removed and the latency was 
recorded as $600 \mathrm{~s}$. By the end of eight trials on day 1 , all animals retrieved the food within $30 \mathrm{~s}$. On day 2, animals were trained for two trials (1 min intertrial interval) with the reward partially buried in the sand followed by another two trials with the reward completely buried but just underneath the surface of the sand. Animals were allowed to explore for a maximum of 10 min to retrieve the food reward, but latency was not recorded. On day 3, animals were trained for four trials per block for two blocks with the reward placed at the bottom of the dish and completely buried in sand. The latency of retrieval on each trial was recorded as on day 1 .

Olfactory discrimination acquisition. The day after completion of pretraining, animals were subjected to the olfactory discrimination acquisition session for four trials per block, two blocks per day as in pretraining, and for 7 consecutive days. Both dishes were filled with sand and presented on each trial; one containing sand scented with $100 \mu \mathrm{l}$ of $10 \mathrm{~mm}$ isoamyl acetate (IAA) and a piece of food reward placed at the bottom of the dish, while the other dish was scented with $10 \mathrm{~mm}$ citralva with no food reward. The two dishes were placed on either the left or right side randomly as long as each dish was placed on each side twice per block, but no more than three consecutive times in each day. After the apparatus with sand and food was placed in the cage in each trial, if the animal's first response was to dig the IAA-scented dish, the animal was allowed to dig until it retrieved the food and the trial was recorded as correct. If the animal's first response was to dig the citralva-scented dish, the animal was still allowed to dig until it left this side. Then the apparatus was raised up and removed quickly before the animal accessed the IAA-scented dish, and the trial was recorded as incorrect.

Olfactory discrimination between structurally similar odorants. Animals were subjected to this test the day after the completion of olfactory discrimination acquisition. Mice were trained four trials per block, two blocks per day as in olfactory discrimination acquisition, for 5 consecutive days to discriminate between a pair of structurally similar odorants, $100 \mathrm{~mm}$ limonene $(+)$ and limonene $(-)$, followed by another $6 \mathrm{~d}$ to discriminate between $100 \mathrm{~mm}$ butanol and pentanol. Food reward was placed at the bottom of the dish under sand scented with limonene (-) or pentanol, respectively.

\section{Statistical analysis}

All data were expressed as mean \pm SEM. Pairwise comparison of the means was analyzed by Student's $t$ test, two-tailed analysis. One-way ANOVA was used to analyze in vivo data comparing across the control groups and the experimental group. n.s., not significant; ${ }^{*} p<0.05$; ${ }^{* *} p<$ 0.01 .

\section{Results \\ Conditional deletion of ERK5 in neural stem cells results in smaller $\mathrm{OB}$}

We previously reported that ERK5 expression in the brain is developmentally regulated. It is high during early embryonic development and gradually declines as the brain matures (Watson et al., 2001; Liu et al., 2003; Shalizi et al., 2003; Finegan et al., 2009). To better characterize the ERK5 expression profile during the period of OB development, we examined ERK5 protein expression in the lateral ganglionic eminence of embryonic brains or the SVZ of postnatal and mature brains, which were sites where OB interneurons are generated. High levels of ERK5 protein were found uniformly in all regions examined in the embryonic brains, however, ERK5 expression decreased significantly during postnatal brain development (Fig. $1 A-E, A^{\prime}-E^{\prime}$ ). At P28 and 6 months postnatally, ERK5 expression was detected in the SVZ (Fig. $1 D, E, D^{\prime}, E^{\prime}$ ) and in the core of the granule cell layer of the OB (Fig. $1 F, G, F^{\prime}, G^{\prime}$ ), sites of ongoing adult neurogenesis along the $\mathrm{SVZ}-\mathrm{OB}$ pathway.

To investigate if ERK5 signaling plays an essential role in the development of the nervous system in vivo, we generated ERK5 conditional knock-out (cKO) mice in which the erk5 gene was deleted in Nestin-expressing neural stem/progenitor cells during development. This was achieved by crossing the Nestin-Cre mouse (Tronche et al., 1999) with an erk5 floxed allele mouse (Wang et al., 2006c) to yield the Nestin-Cre/ERK5 ${ }^{\text {loxP/loxP }}$ mouse (ERK5 cKO). The Cre recombinase activity is present in the nervous system by E11.5 (assuming plug day as E0.5) in this line of Nestin-Cre driver mouse and is primarily expressed in cells expressing Nestin, a marker for neural stem cells (Tronche et al., 1999). Therefore, this approach confines erk5 gene deletion to neural stem cells and their progenies in the nervous system during embryonic development and in adulthood. Male Nestin-Cre/ ERK5 ${ }^{\text {loxP/+ }}$ and female ERK $5^{\text {loxP/loxP }}$ mice were mated to generate ERK5 cKO (Nestin-Cre/ERK5 $5^{\text {loxP/loxP }}$ ) and wild-type (WT) control littermates (ERK $5^{\text {loxP/loxP }}$ and ERK $5^{\text {loxP/+ }}$ ) for experiments. We observed efficient reduction of ERK5 protein expression in virtually all brain regions of the ERK5 mutant mouse during development, including the lateral ganglionic eminence in embryonic brains, and the SVZ and OB of postnatal and mature brains (Fig. $1 H-N, H^{\prime}-N^{\prime}$ ). The ERK5 cKO mutants were otherwise viable and appeared normal.

The overall structure of the brains of ERK 5 cKO mutants was normal at P28 (data not shown), a time point when mouse brain development is complete. However, the size of the OB was noticeably smaller at this time (Fig. $2 \mathrm{~A}$ ). The relative $\mathrm{OB}$ volume, measured using an unbiased stereological quantification technique, was $22 \%$ smaller in ERK5 cKO mice compared with their littermate controls (Fig. 2B). ERK5 heterozygous littermates $\left(\mathrm{Nestin}-\mathrm{Cre} / \mathrm{ERK} 5^{\mathrm{loxP} /+}\right)$, which also carry the Nestin-Cre trans- 
A
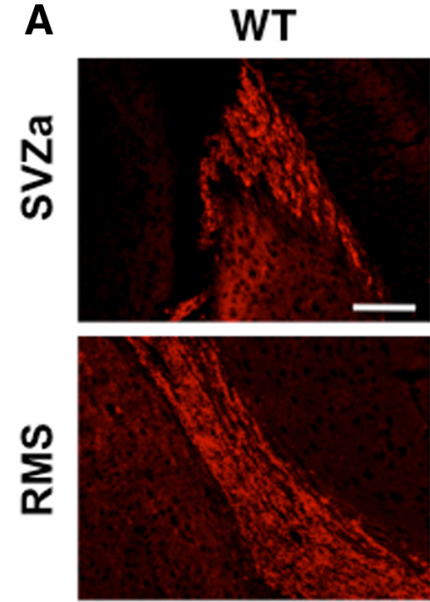

ช๊

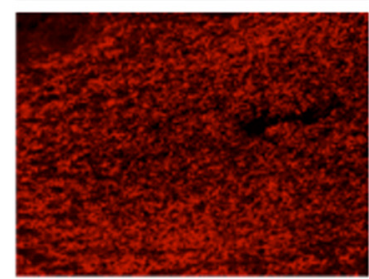

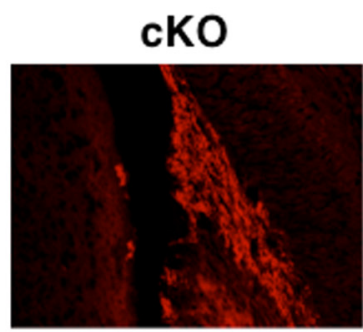
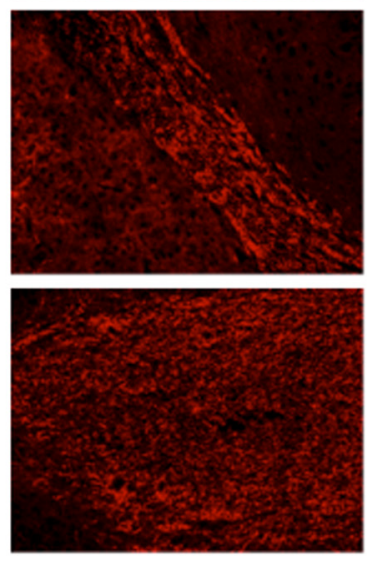

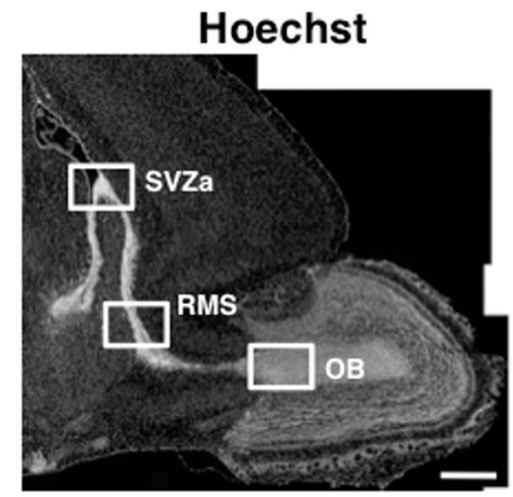

B

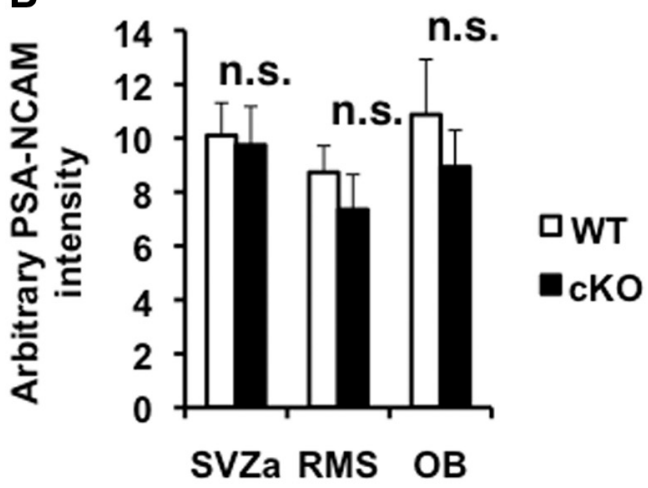

Figure 7. ERK5 deletion does not affect neuroblast migration to the OB. Parasagittal sections of P14 ERK5 WT and cKO brains were subjected to PSA-NCAM immunostaining. $\boldsymbol{A}$, Representative images of PSA-NCAM staining on three locations - SVZa, RMS, and the core of the OB corresponding to the three boxed areas in the montaged Hoechst-stained image-along the SVZa-RMS-OB path. Scale bar, $100 \mu \mathrm{m}$. B, Quantification of the PSA-NCAM staining intensity. n.S., Not significant.

gene, did not have a smaller OB. The small OB phenotype of ERK $5 \mathrm{cKO}$ mice was retained at the age of 6 months old (Fig. 2D).

The OB has a six-layered structure (Wachowiak and Shipley, 2006; Whitman and Greer, 2009). Targeted deletion of ERK5 did not affect the general organization of the layers, the development of lamina, or the total number of glomeruli (Fig. $2 \mathrm{~A}$; data not shown). To determine whether the size of all six layers was affected uniformly, the volume of each layer was measured using the Stereo Investigator software. The granule cell layer, the innermost layer where $>90 \%$ of $\mathrm{OB}$ neurons reside, was most affected by conditional ERK5 deletion (Fig. 2C). The fact that the olfactory nerve layer, composed primarily of afferent fibers from the main olfactory epithelium, was not affected suggests that targeted ERK5 deletion may impair OB development by attenuating OB neurogenesis.

\section{ERK5 deletion reduces the number of GABAergic interneurons in the $\mathrm{OB}$}

To determine whether the reduction in OB size was the result of a reduced number of neurons generated, an antibody against NeuN, which is ubiquitously expressed in the nuclei of most mature neurons, was used to label the OB at P28. Indeed, the density of $\mathrm{NeuN}^{+}$cells in the granule cell layer and glomerular layer was reduced by 21 and $26 \%$ in ERK 5 cKO mice, respectively (Fig. 3).

We also examined the subtypes of neurons that were affected in the OB of ERK5 cKO mice. ERK5 deletion did not change the cell density of mitral cells, identified by an anti-reelin antibody (Fig. 4A-C). Granule cells, the inhibitory interneurons in the granule cell layer of the $\mathrm{OB}$, are all GABAergic (Mugnaini et al., 1984b; Parrish-Aungst et al., 2007). The periglomerular neurons are a heterogeneous population of interneurons surrounding the glomeruli (Allen et al., 2007; Parrish-Aungst et al., 2007; BatistaBrito et al., 2008). The largest subpopulation of periglomerular neurons is GABAergic; a significant portion of which coexpress nonoverlapping molecular markers including $\mathrm{TH}$, a marker for dopaminergic neurons, or calcium binding proteins Calretinin or Calbindin (Mugnaini et al., 1984a; Panzanelli et al., 2007; Parrish-Aungst et al., 2007). Many, but not all $\mathrm{TH}^{+}$, , Calretinin ${ }^{+}$, or Calbindin $^{+}$cells are GABAergic (Parrish-Aungst et al., 2007; Batista-Brito et al., 2008). Immunoreactivity for GAD67, a marker for GABAergic neurons, was reduced $31 \%$ or $34 \%$ in the granule cell layer (Fig. $4 D-F$ ) and glomerular layer (Fig. $4 J-L$ ) of ERK5 cKO mice, respectively. ERK5 deletion also reduced the density of $\mathrm{TH}^{+}$dopaminergic neurons (Fig. 4M-O). However, the numbers of Calbindin ${ }^{+}$cells in the glomerular layer and Calretinin ${ }^{+}$cells in both granule cell layer and glomerular layer were not affected (Fig. 4G-I,P-U). These data suggest a critical role for ERK5 in the generation of GABAergic interneurons and $\mathrm{TH}^{+}$interneurons in the development of the OB.

ERK5 deletion impairs OB neurogenesis by attenuating progenitor proliferation and increasing apoptosis

To gain insight into the mechanisms whereby ERK 5 regulates $\mathrm{OB}$ neurogenesis, we determined whether ERK5 deletion affects cell proliferation and migration in the anterior SVZ and RMS and on apoptosis in the SVZ and OB. Proliferation was assessed by a $2 \mathrm{~h}$ BrdU treatment to label cells in the $S$ phase of the cell cycle. ERK5 deletion significantly reduced the number of proliferating $\mathrm{BrdU}^{+}$cells at P0 and P7 (Fig. 5A-E). However, by P14, the time 
point marking the end of a phase of rapid OB interneuron production, ERK5 deletion did not affect BrdU incorporation. Concomitantly, P0 ERK5 cKO brains have reduced volumes of anterior SVZRMS and enlarged lateral ventricles at P0 although the differences became insignificant thereafter (Fig. $5 F-I$ ). This is consistent with the report that the rate of progenitor cell proliferation correlates with the size of the SVZ and RMS during development (Li et al., 2009). ERK5 deletion did not affect the stem cell pool in the SVZ at P28, determined by IHC for GFAP (data not shown) and Sox2 (Fig. 6).

In the postnatal forebrain, the proliferating neural precursors in the anterior SVZ migrate tangentially along the RMS to the core of the $\mathrm{OB}$ where they migrate to the granule cell layer and glomerular layer and differentiate into mature interneurons. Defects in neuroblast chain migration result in small, hypocellular, and disorganized $\mathrm{OB}$ exemplified in transgenic mouse models in which NCAM or Girdin have been deleted (Cremer et al., 1994; Gheusi et al., 2000; Wang et al., 2011). We therefore investigated if ERK5 deletion interferes with tangential migration in the RMS, thus contributing to the reduced number of neurons in the $\mathrm{OB}$ of ERK5 cKO mice. We examined immunoreactivity for PSA-NCAM, a marker for migrating neuroblasts, on three locations along the entire tangential migration pathway of P14 brains: the anterior SVZ, the middle of the RMS, and the core of OB where tangential migration ends. The pattern of PSA-NCAM immunostaining and the relative orientation of PSA-NCAM ${ }^{+}$ cells were very similar between WT and ERK5 cKO mice at all three locations examined (Fig. 7A). There was also no significant difference in the PSA-NCAM staining intensity between the two mouse strains (Fig. 7B), suggesting that ERK5 signaling is not essential for neuronal migration from RMS to the OB.

In addition to proliferation and migration, apoptosis also plays a critical role in neurogenesis and ERK5 has been implicated in promoting neuronal survival and inhibiting apoptosis in cultures (Watson et al., 2001; Liu et al., 2003; Shalizi et al., 2003; Finegan et al., 2009). We used TUNEL to identify apoptotic cells. Strikingly, ERK5 deletion caused a 65 and $45 \%$ increase in apoptosis in the anterior SVZ and RMS of P0 and P7 mouse brains, respectively (Fig. $8 A, B$ ). This finding was confirmed by increased immunoreactivity for active caspase3, another apoptosis marker (Fig. 8C,D). Furthermore, ERK5 deletion increased apoptosis by $61 \%$ in the granule cell layer and $75 \%$ in the glomerular layer of the OB, respectively (Fig. $8 E, F)$. Together, these data suggest that ERK5 is required for the survival of progenitor cells in the SVZ-RMS during the peak production of olfactory interneurons between $\mathrm{P} 0$ and $\mathrm{P} 7$ and of postmitotic neurons in the granule cell layer and glomerular layer of the $\mathrm{OB}$.
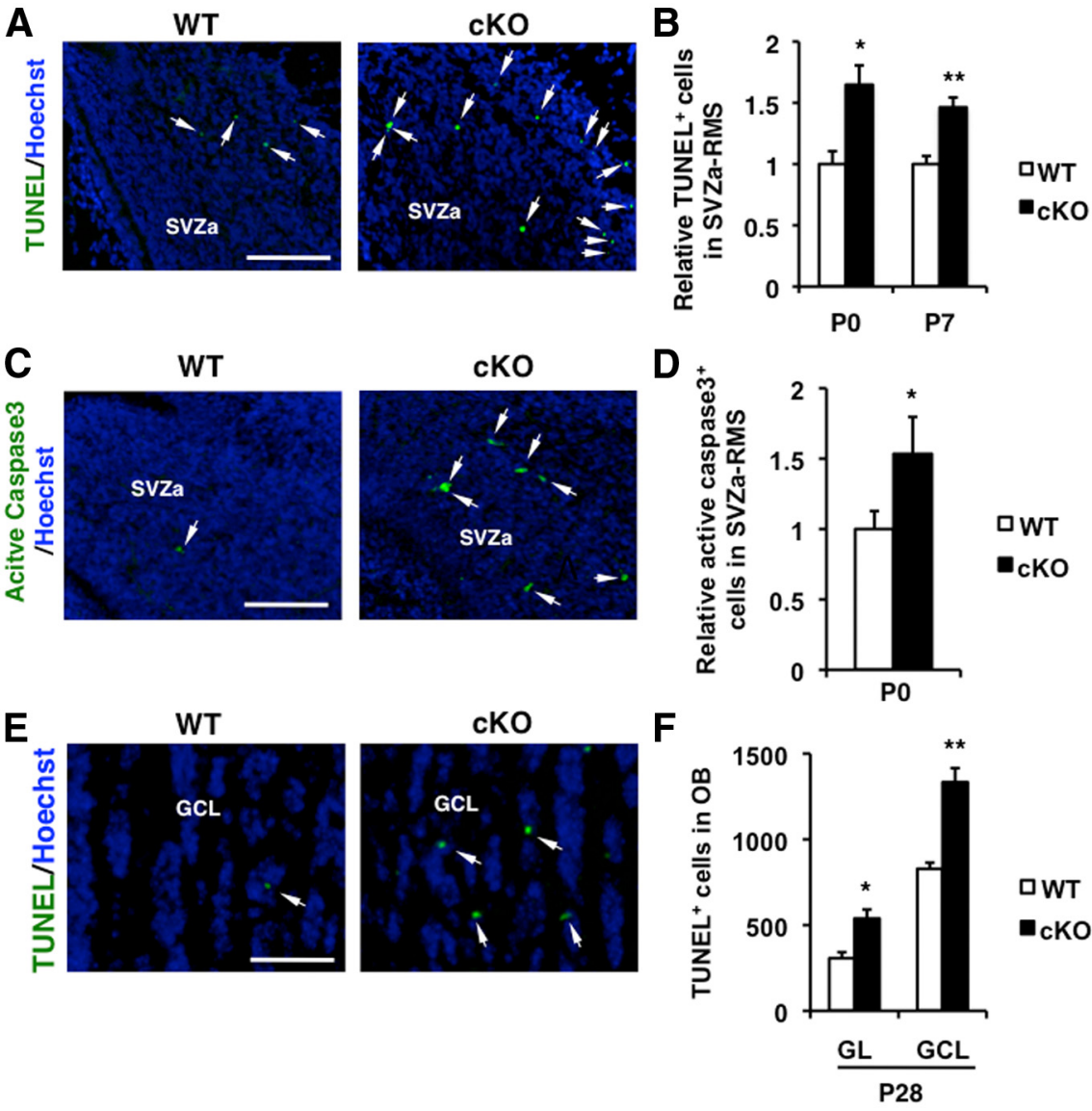

cKO

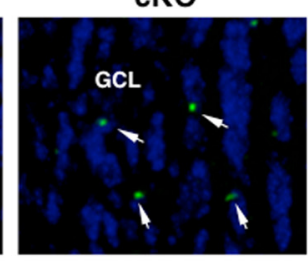

P28

Figure 8. ERK5 deletion increases apoptosis in both the anterior SVZ-RMS and the OB. Parasagittal sections of WT and ERK5 CKO brains at P0 and P7 were subjected to TUNEL and/or active caspase3 immunostaining to analyze the apoptosis in SVZa-RMS a fication of total number of active caspase ${ }^{+}$cells per SVZa-RMS. $E$, Representative images of TUNEL (green) in the GCL of the OB at P28. Scale bar, $50 \mu \mathrm{m}$. $\boldsymbol{F}$, Quantification of total number of TUNEL ${ }^{+}$cells in $\mathrm{GCL}$ and GL per $0 \mathrm{~B} .{ }^{*} p<0.05 ;{ }^{* *} p<0.01$.

ERK5 deletion does not affect the development of the main olfactory epithelium or innervation of the $\mathrm{OB}$

We investigated the structure and function of the main olfactory epithelium of ERK5 cKO mice and their littermate controls. ERK5 deletion did not alter the thickness of the main olfactory epithelium examined by Nissl staining (Fig. 9A). It also did not affect the expression of AC3 in the olfactory cilia (Fig. 9B), a key signaling molecule for olfaction in the main olfactory epithelium and a marker protein for olfactory cilia (Wong et al., 2000).

To test if the main olfactory epithelium of ERK 5 cKO mice is functionally normal, we measured EOG responses to odorevoked field potentials of the main olfactory epithelium tissue. We found no differences between ERK5 cKO mice and WT littermates in EOG responses to several structurally distinct odorants including citralva, IAA, limonene $(-)$, and ethyl vanillin (Fig. 9C,D). This indicates that ERK5 cKO mice do not have defects in proximal olfactory signaling in the main olfactory epithelium.

We also examined the innervation of the OB by olfactory sensory neurons, determined by immunostaining using an antibody against OMP. OMP is specifically expressed in the soma and axons of mature olfactory sensory neurons which project to the 
A

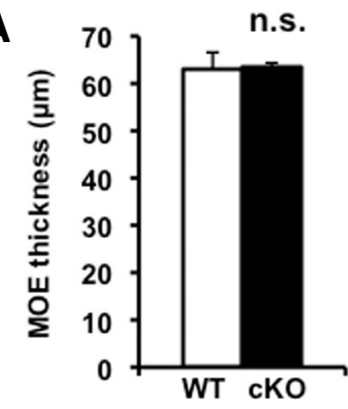

C

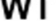

cKO

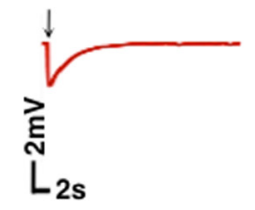

D

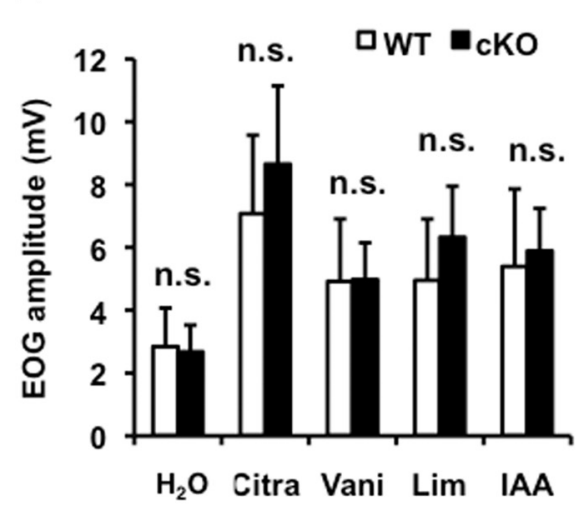

B
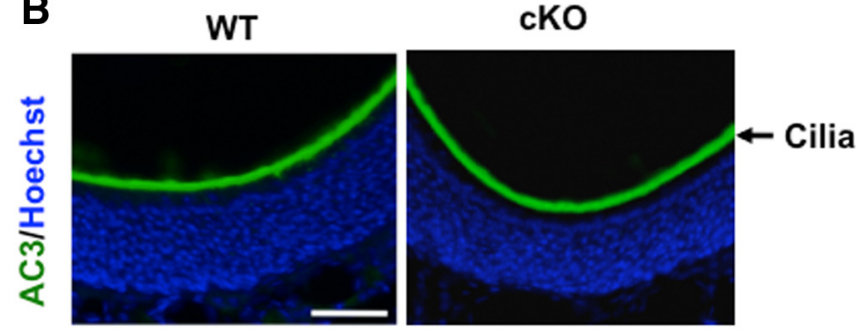

Ethyl

Citralva vanillin

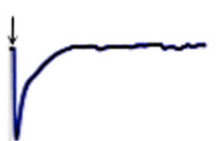

Limonene (-)

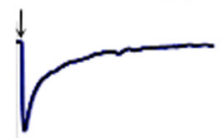

Isoamyl acetate
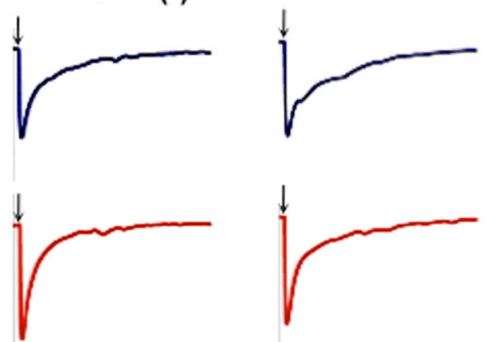

PO

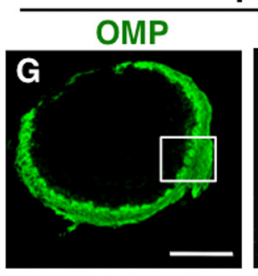

OMP
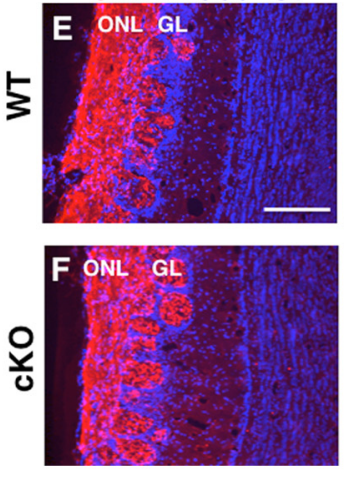
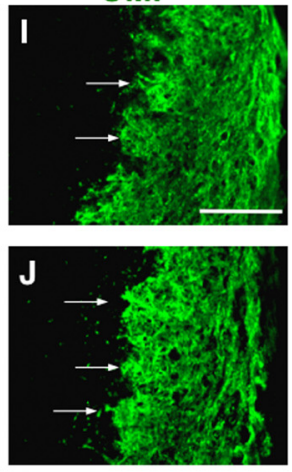

Figure 9. ERK5 deletion does not affect the development of the main olfactory epithelium (MOE), the EOG response of the MOE to odorants, or the innervation of the OB. $A$, ERK5 deletion does not change the thickness of the MOE, measured after Nissl staining. $\boldsymbol{B}$, ERK5 deletion does not alter the immunoreactive profile of AC3 in the cilia layer of the MOE. Scale bar, $50 \mu \mathrm{m}$. $\boldsymbol{C}$, Odorant-stimulated EOG responses were similar in the MOE prepared from ERK5 WT and cKO mice. The MOE tissue was air-puffed with $\mathrm{H}_{2} 0$, citralva ( 1 mM), ethyl vanillin ( 100 $\mu \mathrm{m}$ ), limonene ( - ) $(10 \mathrm{~mm})$, and IAA (1 mm). The membrane potential was recorded by EOG. Arrows point to the start of odorant administration. D, Summary of the mean EOG amplitudes in response to odorants. Citra, citralva; Vani, ethyl vanillin; Lim, limonene ( - ); IAA, isoamyl acetate. $\boldsymbol{E}, \boldsymbol{F}$, ERK5 deletion does not change the immunostaining pattern or intensity for olfactory marker protein (OMP) in the 0B of P28 mice. OMP is a marker of mature olfactory sensory neurons that project to the olfactory nerve layer (ONL) and glomerular layer (GL). Scale bar: (in $\boldsymbol{E}$ ) $\boldsymbol{E}, \boldsymbol{F}, 200 \mu \mathrm{m}$. $\boldsymbol{G}, \boldsymbol{H}$, Representative images of OMP immunostaining of the OB from P0 pups. The pattern of innervation of the OB by olfactory sensory neurons is similar between ERK5 WT and cK0 pups at P0. Scale bar: (in $\boldsymbol{G}$ ) $\mathbf{G}, \boldsymbol{H}, 400 \boldsymbol{\mu m}$. $\boldsymbol{I}, \boldsymbol{J}$, High-magnification images of the boxed areas in $\mathbf{G}$ and $\boldsymbol{H}$, respectively, showing the development of glomerulus-like structures (arrows) in the 0B from both ERK5 WT and cKO pups. Scale bar: (in I) I, J, $100 \mu$ m. n.S., Not significant.

$\mathrm{OB}$, but it is not expressed in other cell types in the OB (Hartman and Margolis, 1975; Lèvai and Strotmann, 2003). Anti-OMP staining, generally found in the olfactory nerve layer and in the glomeruli of the $\mathrm{OB}$, is often used to evaluate olfactory sensory neuron innervation of the OB (Kim and Greer, 2000). OMP staining of ERK5 cKO mutants and WT controls at P28 were very similar in the olfactory nerve layer and in the glomeruli (Fig. $9 E, F)$. Likewise, the OMP staining pattern in the OB of $\mathrm{P} 0 \mathrm{mu}-$ tant mice was much like that of their littermate controls (Fig. $9 G, H)$, and similar developing glomerulus-like structures can be observed (Fig. 9I,J), indicating that the development of glomeruli and establishment of innervation of the OB were not affected by erk5 gene deletion.
ERK5 cKO mice are unable to discriminate between structurally similar odorants

It was important to determine whether reduced $\mathrm{OB}$ neurogenesis causes defects in the animal's ability to detect odorants or to distinguish between structurally similar odorants. ERK5 cKO and WT littermates were subjected to the odorant habituation assay to monitor their ability to sense odorants (Trinh and Storm, 2003; Wang et al., 2006b). In this test, the mouse was first habituated to the presence of a cotton swab soaked in mineral oil in its cage. The time that the mouse sniffed or explored the cotton swab was recorded during four successive trials. This pretraining ensured that sniffing of subsequent odor presentations was not a response to the novel object. Then, we introduced an odor-laced 
cotton swab and the duration of sniffing was recorded (Fig. 10A). A high duration of sniffing upon this initial exposure indicates that the animal detected the novel odorant. Sniffing declined in subsequent trials because the odorant was no longer novel. This test was repeated with three structurally different odorants: octanol, benzaldehyde, and ethyl vanillin. ERK5 cKO mice detected these odorants as well as their WT littermate controls.

Animals were then tested for their ability to discriminate between structurally similar odorants. Two pairs of odorants were used as described previously (Moreno et al., 2009), limonene (+) versus limonene $(-)$, which are enantiomers, and butanol versus pentanol, alcohols with one carbon difference. For each pair of odorants examined using the cotton tip presentation-based test, the test consisted of four habituation trials with limonene $(+)$ followed by one presentation of limonene $(-)$ (Fig. $10 \mathrm{~B}$ ), or four habituation trials with butanol before one presentation of pentanol (Fig. 10C). A significant increase in sniffing duration toward the second odor compared with the fourth presentation of the first odor was a measure of the animal's ability to distinguish between the two similar odorants. ERK5 cKO mice behaved similarly as the WT littermate controls during the four habituation trials of each pair of the odorants, indicating that they can detect the odorants. However, only WT control mice, but not ERK5 cKO mice, were able to distinguish between structurally similar odorants and showed significantly greater interest in the second odorant after repeated presentation of the first odorant.

One might argue that ERK5 cKO and WT mice have differing levels of attraction toward the second odor, thereby confounding the measure of discrimination between the two structurally similar odorants. To rule out this possibility, each pair of odorants was presented to a new cohort of mice simultaneously, and the duration of sniffing to each odorant was recorded. ERK5 WT and cKO mice showed similar levels of sniffing toward each pair of odorants (Fig. 10D), indicating that they do not have any preferences between $(+)$ versus $(-)$ limonene or butanol versus pentanol.

The ability to discriminate between structurally similar odorants was also examined using a second, sand digging-based assay in which animals were trained to use the odor cue to find a food reward that was placed at the bottom of the dish and completely buried in sand (Fig. 11A). We first pretrained WT and ERK5 cKO mice with food on top of or buried in unscented sand. Both genotypes acquired the food retrieval skill equally well (Fig. $11 \mathrm{~B}$ ).

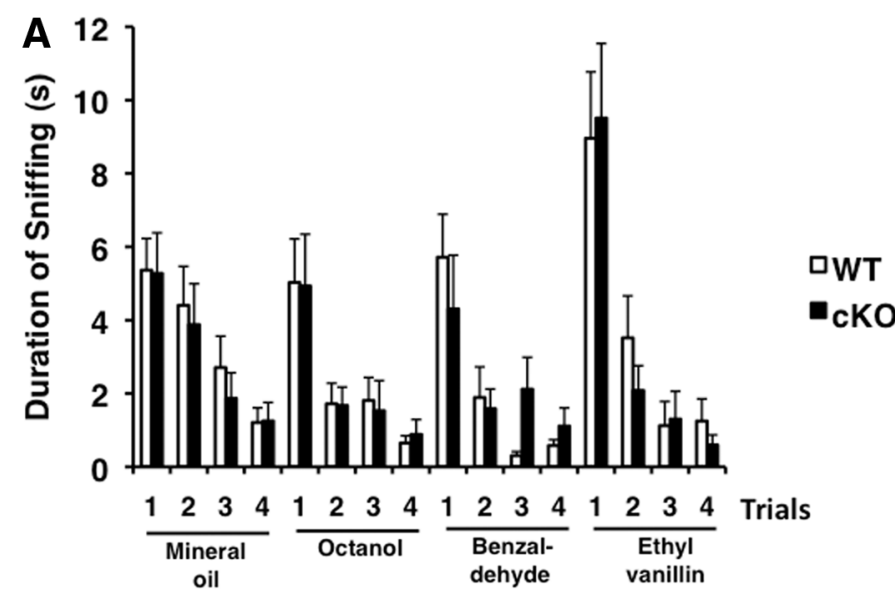

B Limonene (+) vs. Limonene (-) C Butanol vs. Pentanol
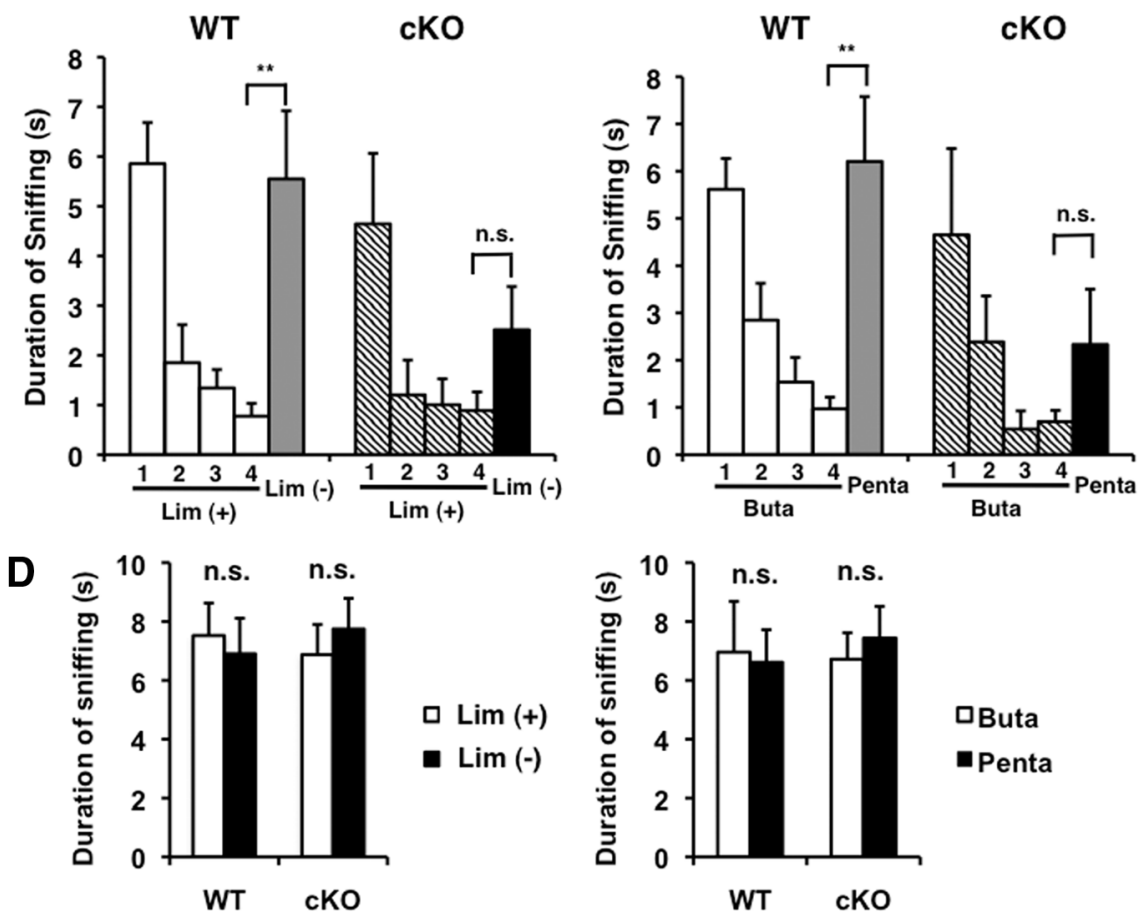

Figure 10. ERK5 CKO mice are deficient in the discrimination of structurally similar odors under a cotton tip presentation-based task. $\boldsymbol{A}$, ERK5 CKO mice are normal in the standard habituation/dishabituation olfaction test. Naive, adult mice were pretrained with four presentations of mineral oil-soaked cotton swabs, then exposed to three structurally different odorants-octanol, benzaldehyde, and ethyl vanillin — with 4 trials per odorant. Both WT and ERK5 CKO mice were able to detect and discriminate between the distinct odorants. $\boldsymbol{B}$, ERK5 CKO mice cannot distinguish between the structurally similar limonene $(+)$ and limonene $(-)$. Animals were exposed to four presentations of limonene $(+)$ followed by one presentation to limonene $(-)$. WT, but not ERK5 CKO mice, sniffed limonene ( - ) significantly more than the fourth presentation of limonene $(+)$, suggesting their ability to discriminate between the two similar odorants. C, Similarly, unlike their WT littermates, ERK5 CKO mice cannot discriminate between butanol and pentanol. D, Neither ERK5 WT nor cKO mice show any preference toward a particular odorant between each pair of the structurally similar ones. Animals were presented simultaneously with two cotton tips laced with a pair of the structurally similar odorants, limonene $(+)$ versus $(-)$, or butanol versus pentanol. Lim, limonene; Buta, butanol; Penta, pentanol. $n \geq$ 10 for WT and $n=9$ for cK0. n.S., Not significant; ${ }^{* *} p<0.01$.

When the sand was scented with IAA or citralva, two structurally unrelated odors, WT animals were able to discriminate the odors quite well and all learned to retrieve the food reward buried under IAA-scented sand by day 6 (97.5\% correct choice) (Fig. 11C). ERK5 cKO mice performed slightly poorer than WT mice and made $85 \%$ correct choice rate by day 7 . When mice were trained to discriminate between the two pairs of structurally similar odorants in this assay, WT mice made $\sim 90 \%$ correct choices by 
A

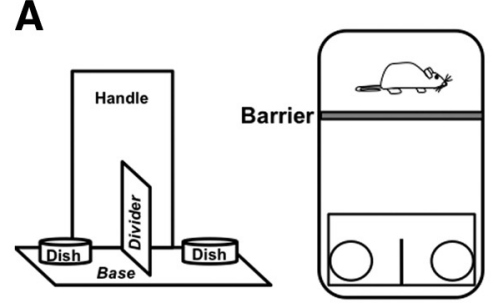

C Isoamyl acetate vs. Citralva

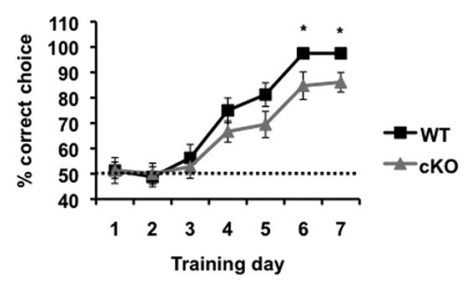

B

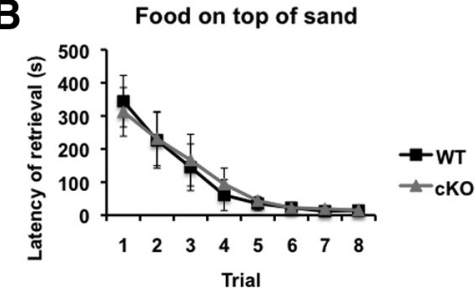

D Limonene (+) vs. Limonene (-)

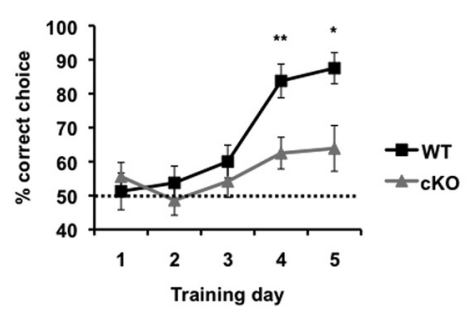

Food deeply buried

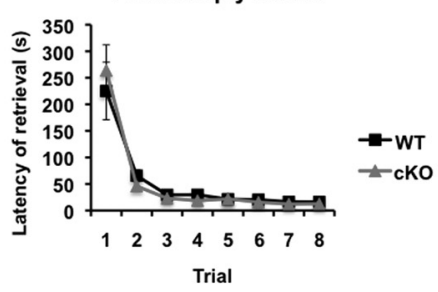

E Butanol vs. Pentanol

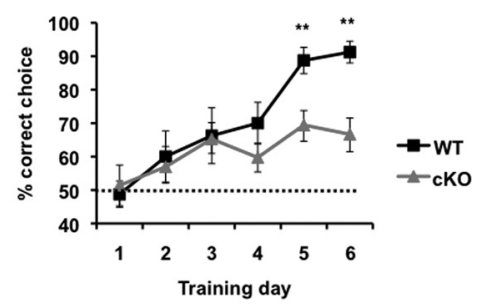

Figure 11. ERK5 cKO mice are deficient in the discrimination of structurally similar odors under a sand digging-based task. $A$, Schematic diagram of the behavior apparatus and set up for the assay. The animal was confined to one end of his home cage by a barrier while the apparatus was lowered to the other end of the cage to deliver the sand-filled dishes and food. The barrier was then removed to allow the animal to investigate the sand dishes and retrieve the food. B, Both ERK5 CKO mice and WT littermate controls learned to retrieve the food reward that is placed on top of the sand or deeply buried in the sand during pretraining sessions. C, Mice were trained to associate an odor cue with the food reward and discriminate two structurally unrelated odors, IAA and citralva. The food reward was buried deeply under the sand scented with IAA. D, ERK5 CKO mice are deficient in distinguishing between the structurally similar limonene (+) versus limonene $(-)$. The food reward was buried deeply under the sand scented with limonene (-).E, Unlike their WT littermates, ERK5 CKO mice cannot discriminate between butanol and pentanol. The food reward was buried deeply under the sand scented with pentanol. $n=10$ and 9 for WT and cK0, respectively. ${ }^{*} p=0.05 ;{ }^{* *} p=0.01$.

day 5 between limonene $(+)$ versus $(-)($ Fig. $11 D)$ or butanol versus pentanol (Fig. $11 E$ ). However, ERK5 cKO mice only made $60-65 \%$ correct choices, only $10-15 \%$ above the $50 \%$ chance level, toward either pair of the odorants. Finally, both ERK5 WT and cKO mice made $50 \%$ correct choice on day 1 for both pairs of the odorants in the sand digging-based assay, confirming the notion that ERK5 cKO mice do not exhibit apparent preference for a specific odorant. Together, these behavior data strongly suggest that ERK5 $\mathrm{cKO}$ mice are deficient in discrimination between structurally similar odorants, and the differences between WT and ERK5 cKO mice are unlikely the result of different levels of attraction toward these structurally similar odorants.

\section{Discussion}

Despite the high levels of expression of ERK5 in both CNS and PNS during development, its role in the development of the mammalian nervous system has not been established. Indeed, several reports claim that ERK5 may be dispensable for development of the nervous system (Hayashi and Lee, 2004; Newbern et al., 2011). However, Hayashi and Lee (2004) presented no experimental data supporting this conclusion and Newbern et al. (2011) did not report the effect of ERK5 deletion on the OB. Therefore, the goal of this study was to determine whether ERK5 MAP kinase plays an essential role in the development of the $\mathrm{OB}$ in vivo. In this study, we generated a conditional ERK5 KO strain in which the erk5 gene was deleted in Nestin-expressing neural stem/progenitor cells. We discovered that ERK5 mutant mice have a smaller OB containing $31-34 \%$ fewer GABAergic interneurons. This reduction of GABAergic neurons is due to decreased proliferation coupled to increased apoptosis along the SVZ-RMS-OB pathway. Although ERK5 mutant mice were able to detect discrete odorants, they were unable to distinguish between structurally similar odorants. These data demonstrate an indispensable role for ERK5 in the development and function of the OB.

ERK5 deletion had no effect on mitral cell production, suggesting that neurogenesis of mitral cells is not regulated by ERK5 signaling. Alternatively, there may have been residual ERK5 protein present in stem cells of ERK5 cKO mice between E11 and E13.5, a period of time when mitral cells are normally produced (Hinds, 1968; Blanchart et al., 2006) because the Nestin-driven Cre expression begins at E11.5 in the Cre driver mice. However, ERK5 deletion decreased the number of GABAergic neurons in the granule cell layer and glomerular layer. It is interesting that, among the different subtypes of interneurons in the glomerular layer, ERK5 deletion impaired the genesis of $\mathrm{TH}^{+}$but not Calretinin $^{+}$or Calbindin ${ }^{+}$interneurons. Since Calretinin ${ }^{+}$or Calbindin ${ }^{+}$interneurons are generated after $\mathrm{TH}^{+}$neurons during development (Batista-Brito et al., 2008), it is unlikely that the lack of effect of ERK5 deletion on their production is because there was still enough residual ERK5 protein expressed. Our data suggest that ERK5 may be important for developmental neurogenesis of GABAergic and $\mathrm{TH}^{+}$interneurons in the $\mathrm{OB}$, but not for Calretinin ${ }^{+}$or Calbindin ${ }^{+}$interneurons.

ERK5 deletion did not seem to affect tangential migration of neuroblasts along the RMS. However, there was a significant reduction of cell proliferation in the anterior SVZ and RMS at P0 and $\mathrm{P} 7$, but not $\mathrm{P} 14$. It is possible that compensatory mechanisms have overcome ERK5 defects by P14 or that the intrinsic properties of neural stem/progenitor cells have changed at P14 and no longer require ERK5 for proliferation. Regardless, our data suggest that ERK5 controls OB interneuron generation at least partially by regulating progenitor cell proliferation during the peak of interneuron production in the developing OB.

ERK5 has been implicated in cellular proliferation in cell lines and in the transformation of cancer cells (Kato et al., 1998; Pearson et al., 2001; Watson et al., 2001; Liu et al., 2003; Shalizi et al., 2003). Hyperactivity of the ERK5 pathway is associated with highly aggressive forms of breast and prostate cancers (EsparísOgando et al., 2002; Mehta et al., 2003). ERK5 may regulate proliferation through its actions at G1/S entry and/or G2/M progression (Wang and Tournier, 2006; Cude et al., 2007). Here 
we present evidence for ERK5 regulation of proliferation of normal cells in vivo, and more specifically, of progenitor cells in the SVZ-RMS during development.

Although studies using primary cultured neurons have suggested a critical role for ERK5 in neurotrophin-induced survival of immature cortical, cerebellar, DRG, and SCG neurons (Watson et al., 2001; Liu et al., 2003; Shalizi et al., 2003; Finegan et al., 2009), whether it plays a role in promoting cell survival in the nervous system in vivo is still an open question. Germ-line deletion of ERK 5 causes lethality at $\sim$ E9.5-10.5 because of cardiovascular defects (Regan et al., 2002; Sohn et al., 2002; Yan et al., 2003). Although high levels of apoptosis (TUNEL ${ }^{+}$cells) were observed in the heads of these animals, there was no evidence that apoptosis occurred in neurons or neural progenitors. In fact, increased apoptosis in the heads of ERK5-null mice was attributed to apoptosis in the cephalic mesenchyme tissue (Yan et al., 2003). In addition, when ERK5 was conditionally deleted in pluripotent neural crest cells, it had no effect on the survival of DRG neurons (Newbern et al., 2011). Interestingly, there is an increase in apoptosis in the SVZ-RMS and the OB of ERK5 cKO mice. Thus, in addition to proliferation, ERK5 also regulates OB neurogenesis by promoting the survival of both precursor cells in the SVZ-RMS pathway and postmitotic neurons in the granule cell layer and glomerular layer of the $\mathrm{OB}$ during development. These data provide in vivo evidence for a pivotal role for ERK5 in the survival of neural precursor cells and postmitotic neurons.

The major effect of ERK5 disruption was a significant decrease in GABAergic interneurons in the OB. There are $\sim 100$ times more local GABAergic interneurons in the $\mathrm{OB}$ than excitatory projection neurons, suggesting that inhibitory neurons play essential roles in the processing of olfactory information. Electrophysiology studies have established that GABAergic synapses mediate negative feedback and lateral inhibition by precisely synchronizing the firing of specific subsets of projection neurons. It is thought that this lateral inhibition and synchronization are necessary for odor discrimination at the behavior level (Shepherd et al., 2007; Lledo et al., 2008; Linster and Cleland, 2009). Interestingly, enhanced synaptic inhibition accelerates odor discrimination in mice (Abraham et al., 2010). Nevertheless, it had not been clearly established that attenuation of interneuron production, either during development or in the adult, impairs behavioral discrimination between odors. Thus, it was still unclear if these inhibitory neurons are required for behavioral odor discrimination. For example, deficits in fine olfactory discrimination correlate with aging and aging-associated reduction of adult neurogenesis (Enwere et al., 2004). However, specific genetic ablation of adult-born interneurons had no effect on odor discrimination even when a significant reduction of adult-born interneurons was observed (Imayoshi et al., 2008; BretonProvencher et al., 2009). NCAM-deficient mice have a smaller $\mathrm{OB}$, reduced number of granule cells in the $\mathrm{OB}$, and are deficient in odor discrimination (Cremer et al., 1994; Gheusi et al., 2000). However, NCAM is expressed in derivatives of all three germ layers during development and not limited to the nervous system (Reyes et al., 1991; Lyons et al., 1992). Since NCAM was deleted globally in the study by Gheusi et al. (2000), it is difficult to ascertain if the deficit in odor discrimination was due to impaired interneuron production in the OB. In fact, these NCAMdeficient mice have smaller brains, and the mitral cells in mutant mice are arranged in multiple rows, compared with a single row in the normal animal (Tomasiewicz et al., 1993; Cremer et al., 1994). Furthermore, NCAM is expressed in olfactory sensory neurons and found in the olfactory nerve layer of the $\mathrm{OB}$ in both mice and human (Rioux et al., 2005; Miller et al., 2010). However, the functionality of olfactory sensory neurons and their innervation to the $\mathrm{OB}$ were not examined.

Here we present evidence that ERK5 $\mathrm{cKO}$ mice, which have $31-34 \%$ fewer GABAergic interneurons, retain their ability to detect odors. However, they are unable to discriminate between structurally similar odorants. Although ERK5 cKO mice cannot distinguish between limonene $(+)$ and limonene $(-)$ in both the cotton tip- and sand digging-based behavior assays, the EOG response to limonene $(-)$ was similar between ERK5 WT and cKO. These data suggest that the behavior deficits of ERK5 cKO mice in discriminating between structurally similar odorants are likely due to changes in the $\mathrm{OB}$, rather than a detection deficiency in the main olfactory epithelium. Collectively, these results suggest a critical role for ERK5 in olfactory behavior, and provide behavioral evidence supporting the hypothesis that inhibitory interneurons are necessary for odor discrimination.

In summary, we have discovered that ERK5 regulates the neurogenesis of interneurons during the development of the $\mathrm{OB}$ and is critical for discrimination between structurally similar odorants.

\section{References}

Abraham NM, Egger V, Shimshek DR, Renden R, Fukunaga I, Sprengel R, Seeburg PH, Klugmann M, Margrie TW, Schaefer AT, Kuner T (2010) Synaptic inhibition in the olfactory bulb accelerates odor discrimination in mice. Neuron 65:399-411.

Adam Y, Mizrahi A (2010) Circuit formation and maintenance-perspectives from the mammalian olfactory bulb. Curr Opin Neurobiol 20:134-140.

Allen ZJ 2nd, Waclaw RR, Colbert MC, Campbell K (2007) Molecular identity of olfactory bulb interneurons: transcriptional codes of periglomerular neuron subtypes. J Mol Histol 38:517-525.

Alvarez-Buylla A, Garcia-Verdugo JM (2002) Neurogenesis in adult subventricular zone. J Neurosci 22:629-634.

Batista-Brito R, Close J, Machold R, Fishell G (2008) The distinct temporal origins of olfactory bulb interneuron subtypes. J Neurosci 28:3966-3975.

Blanchart A, De Carlos JA, López-Mascaraque L (2006) Time frame of mitral cell development in the mice olfactory bulb. J Comp Neurol 496:529-543.

Breton-Provencher V, Lemasson M, Peralta MR 3rd, Saghatelyan A (2009) Interneurons produced in adulthood are required for the normal functioning of the olfactory bulb network and for the execution of selected olfactory behaviors. J Neurosci 29:15245-15257.

Brill MS, Snapyan M, Wohlfrom H, Ninkovic J, Jawerka M, Mastick GS, Ashery-Padan R, Saghatelyan A, Berninger B, Götz M (2008) A dlx2and pax6-dependent transcriptional code for periglomerular neuron specification in the adult olfactory bulb. J Neurosci 28:6439-6452.

Cavanaugh JE, Ham J, Hetman M, Poser S, Yan C, Xia Z (2001) Differential regulation of mitogen-activated protein kinases ERK1/2 and ERK5 by neurotrophins, neuronal activity, and cAMP in neurons. J Neurosci 21:434-443.

Cremer H, Lange R, Christoph A, Plomann M, Vopper G, Roes J, Brown R, Baldwin S, Kraemer P, Scheff S (1994) Inactivation of the N-CAM gene in mice results in size reduction of the olfactory bulb and deficits in spatial learning. Nature 367:455-459.

Cude K, Wang Y, Choi HJ, Hsuan SL, Zhang H, Wang CY, Xia Z (2007) Regulation of the G2-M cell cycle progression by the ERK5-NF\{kappa\}B signaling pathway. J Cell Biol 177:253-264.

Cundiff P, Liu L, Wang Y, Zou J, Pan YW, Abel G, Duan X, Ming GL, Englund C, Hevner R, Xia Z (2009) ERK5 MAP kinase regulates Neurogenin1 during cortical neurogenesis. PLoS ONE 4:e5204.

Dellovade TL, Pfaff DW, Schwanzel-Fukuda M (1998) Olfactory bulb development is altered in small-eye (Sey) mice. J Comp Neurol 402:402-418.

English JM, Vanderbilt CA, Xu S, Marcus S, Cobb MH (1995) Isolation of MEK5 and differential expression of alternatively spliced forms. J Biol Chem 270:28897-28902.

Enwere E, Shingo T, Gregg C, Fujikawa H, Ohta S, Weiss S (2004) Aging 
results in reduced epidermal growth factor receptor signaling, diminished olfactory neurogenesis, and deficits in fine olfactory discrimination. J Neurosci 24:8354-8365.

Esparís-Ogando A, Díaz-Rodríguez E, Montero JC, Yuste L, Crespo P, Pandiella A (2002) Erk5 participates in neuregulin signal transduction and is constitutively active in breast cancer cells overexpressing ErbB2. Mol Cell Biol 22:270-285.

Finegan KG, Wang X, Lee EJ, Robinson AC, Tournier C (2009) Regulation of neuronal survival by the extracellular signal-regulated protein kinase 5 . Cell Death Differ 16:674-683.

Gheusi G, Cremer H, McLean H, Chazal G, Vincent JD, Lledo PM (2000) Importance of newly generated neurons in the adult olfactory bulb for odor discrimination. Proc Natl Acad Sci U S A 97:1823-1828.

Haberly LB, Price JL (1977) The axonal projection patterns of the mitral and tufted cells of the olfactory bulb in the rat. Brain Res 129:152-157.

Hartman BK, Margolis FL (1975) Immunofluorescence localization of the olfactory marker protein. Brain Res 96:176-180.

Hayashi M, Lee JD (2004) Role of the BMK1/ERK5 signaling pathway: lessons from knockout mice. J Mol Med 82:800-808.

Hinds JW (1968) Autoradiographic study of histogenesis in the mouse olfactory bulb. I. Time of origin of neurons and neuroglia. J Comp Neurol 134:287-304.

Imayoshi I, Sakamoto M, Ohtsuka T, Takao K, Miyakawa T, Yamaguchi M, Mori K, Ikeda T, Itohara S, Kageyama R (2008) Roles of continuous neurogenesis in the structural and functional integrity of the adult forebrain. Nat Neurosci 11:1153-1161.

Kato Y, Tapping RI, Huang S, Watson MH, Ulevitch RJ, Lee JD (1998) $\mathrm{Bmk1/Erk5}$ is required for cell proliferation induced by epidermal growth factor. Nature 395:713-716.

Kim H, Greer CA (2000) The emergence of compartmental organization in olfactory bulb glomeruli during postnatal development. J Comp Neurol 422:297-311.

Kohwi M, Osumi N, Rubenstein JL, Alvarez-Buylla A (2005) Pax6 is required for making specific subpopulations of granule and periglomerular neurons in the olfactory bulb. J Neurosci 25:6997-7003.

Lee JD, Ulevitch RJ, Han J (1995) Primary structure of BMK1: a new mammalian map kinase. Biochem Biophys Res Commun 213:715-724.

Lèvai O, Strotmann J (2003) Projection pattern of nerve fibers from the septal organ: DiI-tracing studies with transgenic OMP mice. Histochem Cell Biol 120:483-492.

Li X, Tang X, Jablonska B, Aguirre A, Gallo V, Luskin MB (2009) p27(KIP1) regulates neurogenesis in the rostral migratory stream and olfactory bulb of the postnatal mouse. J Neurosci 29:2902-2914.

Linster C, Cleland TA (2009) Glomerular microcircuits in the olfactory bulb. Neural Netw 22:1169-1173.

Liu L, Cavanaugh JE, Wang Y, Sakagami H, Mao Z, Xia Z (2003) ERK5 activation of MEF2-mediated gene expression plays a critical role in BDNF-promoted survival of developing but not mature cortical neurons. Proc Natl Acad Sci U S A 100:8532-8537.

Liu L, Cundiff P, Abel G, Wang Y, Faigle R, Sakagami H, Xu M, Xia Z (2006) Extracellular signal-regulated kinase (ERK) 5 is necessary and sufficient to specify cortical neuronal fate. Proc Natl Acad Sci U S A 103:9697-9702.

Lledo PM, Saghatelyan A, Lemasson M (2004) Inhibitory interneurons in the olfactory bulb: from development to function. Neuroscientist 10:292-303.

Lledo PM, Merkle FT, Alvarez-Buylla A (2008) Origin and function of olfactory bulb interneuron diversity. Trends Neurosci 31:392-400.

Long JE, Garel S, Depew MJ, Tobet S, Rubenstein JL (2003) DLX5 regulates development of peripheral and central components of the olfactory system. J Neurosci 23:568-578.

Long JE, Garel S, Alvarez-Dolado M, Yoshikawa K, Osumi N, Alvarez-Buylla A, Rubenstein JL (2007) Dlx-dependent and -independent regulation of olfactory bulb interneuron differentiation. J Neurosci 27:3230-3243.

Luskin MB (1998) Neuroblasts of the postnatal mammalian forebrain: their phenotype and fate. J Neurobiol 36:221-233.

Lyons GE, Moore R, Yahara O, Buckingham ME, Walsh FS (1992) Expression of NCAM isoforms during skeletal myogenesis in the mouse embryo. Dev Dyn 194:94-104.

Mehta PB, Jenkins BL, McCarthy L, Thilak L, Robson CN, Neal DE, Leung HY (2003) MEK5 overexpression is associated with metastatic prostate cancer, and stimulates proliferation, MMP-9 expression and invasion. Oncogene 22:1381-1389.
Mihalick SM, Langlois JC, Krienke JD, Dube WV (2000) An olfactory discrimination procedure for mice. J Exp Anal Behav 73:305-318.

Miller AM, Maurer LR, Zou DJ, Firestein S, Greer CA (2010) Axon fasciculation in the developing olfactory nerve. Neural Dev 5:20.

Moreno MM, Linster C, Escanilla O, Sacquet J, Didier A, Mandairon N (2009) Olfactory perceptual learning requires adult neurogenesis. Proc Natl Acad Sci U S A 106:17980-17985.

Mugnaini E, Oertel WH, Wouterlood FF (1984a) Immunocytochemical localization of GABA neurons and dopamine neurons in the rat main and accessory olfactory bulbs. Neurosci Lett 47:221-226.

Mugnaini E, Wouterlood FG, Dahl AL, Oertel WH (1984b) Immunocytochemical identification of GABAergic neurons in the main olfactory bulb of the rat. Arch Ital Biol 122:83-113.

Newbern JM, Li X, Shoemaker SE, Zhou J, Zhong J, Wu Y, Bonder D, Hollenback S, Coppola G, Geschwind DH, Landreth GE, Snider WD (2011) Specific functions for ERK/MAPK signaling during PNS development. Neuron 69:91-105.

Panzanelli P, Fritschy JM, Yanagawa Y, Obata K, Sassoè-Pognetto M (2007) GABAergic phenotype of periglomerular cells in the rodent olfactory bulb. J Comp Neurol 502:990-1002.

Parrish-Aungst S, Shipley MT, Erdelyi F, Szabo G, Puche AC (2007) Quantitative analysis of neuronal diversity in the mouse olfactory bulb. J Comp Neurol 501:825-836.

Pearson G, English JM, White MA, Cobb MH (2001) ERK5 and ERK2 cooperate to regulate NF-kappaB and cell transformation. J Biol Chem 276:7927-7931.

Regan CP, Li W, Boucher DM, Spatz S, Su MS, Kuida K (2002) Erk5 null mice display multiple extraembryonic vascular and embryonic cardiovascular defects. Proc Natl Acad Sci U S A 99:9248-9253.

Reyes AA, Small SJ, Akeson R (1991) At least 27 alternatively spliced forms of the neural cell adhesion molecule mRNA are expressed during rat heart development. Mol Cell Biol 11:1654-1661.

Rioux L, Gelber EI, Parand L, Kazi HA, Yeh J, Wintering R, Bilker W, Arnold SE (2005) Characterization of olfactory bulb glomeruli in schizophrenia. Schizophr Res 77:229-239.

Rosselli-Austin L, Altman J (1979) The postnatal development of the main olfactory bulb of the rat. J Dev Physiol 1:295-313.

Schwob JE, Price JL (1978) The cortical projection of the olfactory bulb: development in fetal and neonatal rats correlated with quantitative variations in adult rats. Brain Res 151:369-374.

Shalizi A, Lehtinen M, Gaudilliere B, Donovan N, Han J, Konishi Y, Bonni A (2003) Characterization of a neurotrophin signaling mechanism that mediates neuron survival in a temporally specific pattern. J Neurosci 23:7326-7336.

Shepherd GM, Chen WR, Willhite D, Migliore M, Greer CA (2007) The olfactory granule cell: from classical enigma to central role in olfactory processing. Brain Res Rev 55:373-382.

Shingo T, Gregg C, Enwere E, Fujikawa H, Hassam R, Geary C, Cross JC, Weiss S (2003) Pregnancy-stimulated neurogenesis in the adult female forebrain mediated by prolactin. Science 299:117-120.

Sohn SJ, Sarvis BK, Cado D, Winoto A (2002) ERK5 MAPK regulates embryonic angiogenesis and acts as a hypoxia-sensitive repressor of vascular endothelial growth factor expression. J Biol Chem 277:43344-43351.

Stenman J, Toresson H, Campbell K (2003) Identification of two distinct progenitor populations in the lateral ganglionic eminence: implications for striatal and olfactory bulb neurogenesis. J Neurosci 23:167-174.

Sundberg H, Døving K, Novikov S, Ursin H (1982) A method for studying responses and habituation to odors in rats. Behav Neural Biol 34:113-119.

Tomasiewicz H, Ono K, Yee D, Thompson C, Goridis C, Rutishauser U, Magnuson T (1993) Genetic deletion of a neural cell adhesion molecule variant (N-CAM-180) produces distinct defects in the central nervous system. Neuron 11:1163-1174.

Trinh K, Storm DR (2003) Vomeronasal organ detects odorants in absence of signaling through main olfactory epithelium. Nat Neurosci 6:519-525.

Tronche F, Kellendonk C, Kretz O, Gass P, Anlag K, Orban PC, Bock R, Klein R, Schütz G (1999) Disruption of the glucocorticoid receptor gene in the nervous system results in reduced anxiety. Nat Genet 23:99-103.

van Velthoven CT, Kavelaars A, van Bel F, Heijnen CJ (2010) Repeated mesenchymal stem cell treatment after neonatal hypoxia-ischemia has distinct effects on formation and maturation of new neurons and oligodendrocytes leading to restoration of damage, corticospinal motor tract activity, and sensorimotor function. J Neurosci 30:9603-9611. 
Wachowiak M, Shipley MT (2006) Coding and synaptic processing of sensory information in the glomerular layer of the olfactory bulb. Semin Cell Dev Biol 17:411-423.

Waclaw RR, Allen ZJ 2nd, Bell SM, Erdélyi F, Szabó G, Potter SS, Campbell K (2006) The zinc finger transcription factor Sp8 regulates the generation and diversity of olfactory bulb interneurons. Neuron 49:503-516.

Wang X, Tournier C (2006) Regulation of cellular functions by the ERK5 signalling pathway. Cell Signal 18:753-760.

Wang Y, Su B, Xia Z (2006a) Brain-derived neurotrophic factor activates ERK5 in cortical neurons via a rap1-MEKK2 signaling cascade. J Biol Chem 281:35965-35974.

Wang Z, Balet Sindreu C, Li V, Nudelman A, Chan GC, Storm DR (2006b) Pheromone detection in male mice depends on signaling through the type 3 adenylyl cyclase in the main olfactory epithelium. J Neurosci 26:7375-7379.

Wang X, Finegan KG, Robinson AC, Knowles L, Khosravi-Far R, Hinchliffe KA, Boot-Handford RP, Tournier C (2006c) Activation of extracellular signal-regulated protein kinase 5 downregulates FasL upon osmotic stress. Cell Death Differ 13:2099-2108.

Wang Y, Kaneko N, Asai N, Enomoto A, Isotani-Sakakibara M, Kato T, Asai M, Murakumo Y, Ota H, Hikita T, Namba T, Kuroda K, Kaibuchi K, Ming GL, Song H, Sawamoto K, Takahashi M (2011) Girdin is an intrinsic regulator of neuroblast chain migration in the rostral migratory stream of the postnatal brain. J Neurosci 31:8109-8122.

Watson FL, Heerssen HM, Bhattacharyya A, Klesse L, Lin MZ, Segal RA
(2001) Neurotrophins use the Erk5 pathway to mediate a retrograde survival response. Nat Neurosci 4:981-988.

Wesson DW, Donahou TN, Johnson MO, Wachowiak M (2008) Sniffing behavior of mice during performance in odor-guided tasks. Chem Senses 33:581-596.

White LE (1965) Olfactory bulb projections of the rat. The Anatomical Record 152:465-479.

Whitman MC, Greer CA (2009) Adult neurogenesis and the olfactory system. Prog Neurobiol 89:162-175.

Wichterle H, Turnbull DH, Nery S, Fishell G, Alvarez-Buylla A (2001) In utero fate mapping reveals distinct migratory pathways and fates of neurons born in the mammalian basal forebrain. Development 128:37593771.

Wong ST, Trinh K, Hacker B, Chan GC, Lowe G, Gaggar A, Xia Z, Gold GH, Storm DR (2000) Disruption of the type III adenylyl cyclase gene leads to peripheral and behavioral anosmia in transgenic mice. Neuron 27:487-497.

Yan L, Carr J, Ashby PR, Murry-Tait V, Thompson C, Arthur JS (2003) Knockout of ERK5 causes multiple defects in placental and embryonic development. BMC Dev Biol 3:11.

Yun K, Potter S, Rubenstein JL (2001) Gsh2 and Pax6 play complementary roles in dorsoventral patterning of the mammalian telencephalon. Development 128:193-205.

Zhou G, Bao ZQ, Dixon JE (1995) Components of a new human protein kinase signal transduction pathway. J Biol Chem 270:12665-12669. 